Boletín de la Sociedad Geológica Mexicana

VOLUMEN 67, NÚM. 2, 2015, P. 185-201

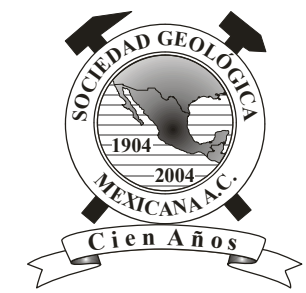

\title{
Historia de la evolución deposicional del lago de Chalco, México, desde el MIS 3
}

\author{
Beatriz Ortega Guerrero ${ }^{1, *}$, Ma. Socorro Lozano García ${ }^{2}$, Margarita Caballero ${ }^{1}$, \\ Dimitris A. Herrera Hernández \\ ${ }^{1}$ Instituto de Geofísica, Universidad Nacional Autónoma de México. Ciudad Universitaria, 04510 México, D.F., México. \\ ${ }^{2}$ Instituto de Geología, Universidad Nacional Autónoma de México. Ciudad Universitaria, 04510 México, D.F., México. \\ ${ }^{3}$ Posgrado en Ciencias de la Tierra, Universidad Nacional Autónoma de México. Ciudad Universitaria, 04510 México, D.F., México. \\ *bortega@geofisica.unam.mx
}

\begin{abstract}
Resumen
Las secuencias sedimentarias lacustres constituyen registros naturales de los cambios climáticos y ambientales ocurridos en su entorno. En este tipo de archivos, las variaciones en los niveles lacustres frecuentemente están asociadas a variaciones climáticas. Sin embargo, en ambientes volcánicos y tectónicos activos, la sedimentación lacustre también puede estar influenciada por fenómenos asociados a estos procesos, ya que éstos pueden modificar el espacio en donde se acumulan los sedimentos, y ejercer un control en el volumen y tipo de material detrítico disponible para su remoción superficial. Por ello, es necesario analizar la influencia de procesos volcánicos y tectónicos para interpretar de manera más acertada la historia de los cambios ambientales y climáticos registrados en las secuencias sedimentarias lacustres en este tipo de ambientes. Además de esta información, a partir de los registros lacustres es posible analizar la recurrencia de la actividad volcánica de una región. La cuenca del lago de Chalco, ubicada en la parte central del Cinturón Volcánico Transmexicano, proporciona un sitio ideal para realizar estudios del impacto de la actividad volcánica y tectónica en la sedimentación lacustre. En este trabajo analizamos el registro sedimentario de los $26.7 \mathrm{~m}$ superiores de la secuencia lacustre, colectado a partir de 7 perforaciones con recuperación de núcleos en diferentes partes de la cuenca. En estas secuencias, determinamos la sucesión de facies sedimentarias y su distribución lateral, analizamos la distribución lateral de las mismas y la arquitectura sedimentaria, así como el impacto de la actividad volcánica y tectónica en el sistema lacustre. La escala temporal de estas secuencias es establecida a partir de fechamientos de radiocarbono, así como del reconocimiento de tefras marcadoras cuya edad es bien conocida. La secuencia compuesta abarca aproximadamente los últimos 60000 años (MIS 3-MIS 1). Se identifican 13 facies sedimentarias, agrupadas en tres categorías principales: 1) detríticas, 2) volcaniclásticas, y 3) biogénicas. Los depósitos volcaniclásticos están constituidos por 18 capas individuales de $1-50 \mathrm{~cm}$ de espesor, de los cuales dos de ellos corresponden a erupciones bien documentadas de los volcanes Popocatépetl y Nevado de Toluca. A partir del análisis de la información derivada de nuestros núcleos y la disponible en la literatura, nosotros sugerimos que el origen de la tefra llamada Gran Ceniza Basáltica, de edad entre $c a .27000$ y 41000 cal A.P., es el volcán monogenético Teuhtli, ubicado en la parte SW de la planicie lacustre. La acumulación de los productos derivados de este volcán modificó la morfología de la cuenca y afectó la sedimentación lacustre y el impacto de esta actividad se registra en la asociación de diatomeas. Es probable que el depocentro de la cuenca, en la actualidad, localizado hacia la parte norte de la planicie lacustre, haya estado ubicado en una porción más al S, controlado por un fallamiento normal sinsedimentario activo hasta hace $c a$. 26500 años.
\end{abstract}

Palabras clave: Sedimentación lacustre, centro de México, ambientes volcánicos, tefracronología, Cuaternario. 


\begin{abstract}
Lacustrine sedimentary sequences are natural archives of past climatic and environmental changes. Lake level fuctuations in these sedimentary records are frequently associated with climatic changes. However, in active volcanic and tectonic settings, lacustrine sedimentation may be altered by these processes by affecting the place of deposition and controlling the volume and type of detrital material available for removal by surface processes. In consequence, it is necessary to analyze volcanic and tectonic processes in order to achieve a better understanding of climatic and environmental changes in the lacustrine sedimentary sequences in this type of environment. Additionally, volcanic material preserved in lacustrine sequences document the recurrence of volcanic activity in a region. Lake Chalco basin, located in the central part of the Transmexican Volcanic Belt, offers an ideal site to evaluate the impact of volcanic and tectonic activity on lacustrine sedimentation. In this work, we analyze the uppermost $26.7 \mathrm{~m}$ of the lacustrine sequence collected in seven cores drilled in different parts of Lake Chalco. In the obtained sequences, we determined the sedimentary facies succession, established their lateral distribution, and analyzed the sedimentary architecture and the impact of volcanotectonic activity on the lacustrine system. The time scale was constructed from radiocarbon determinations and well dated marker tephras from the region. The composite sequence spans the last ca.60000 yr B.P. (MIS 3-MIS 1). Thirteen facies were recognized and grouped into three main categories: 1) detritic, 2) volcaniclastic, and 3) biogenic. Volcaniclastic deposits comprise 18 individual layers $1-50 \mathrm{~cm}$ thick, two of which are from well documented eruptions from Popocatépetl and Nevado de Toluca volcanoes. From our cores and other available information, we suggest that the monogenetic volcano Teuhtli, in the southwestern part of the Chalco lacustrine plain, is the origin of the so called Gran Ceniza Basáltica tephra, dated between ca. 27000 y 41000 cal B.P. The accumulation of Teuhtli derived products altered the basin morphology and affected the lacustrine sedimentation, which is observed in the diatom record. We suggest that an ancient depocentre was located south of the modern lake, and that its location was controlled by synsedimentary normal faulting, active until ca. 26500 years ago
\end{abstract}

Keywords: Lacustrine sedimentation, central Mexico, volcanic settings, tephrachronology, Quaternary.

\section{Introducción}

Las secuencias sedimentarias lacustres de la cuenca de México, ubicada en la parte central del Cinturón Volcánico Transmexicano (Figura 1a), han proporcionado registros de los cambios climáticos y ambientales ocurridos en esta región en los últimos miles de años (Bradbury, 1989; Lozano-García et al., 1993; Caballero y Ortega Guerrero, 1998; Lozano-García y Ortega-Guerrero, 1998). En ambientes volcánico-tectónicos activos, estos procesos pueden ejercer un control en la sedimentación lacustre, por lo que requieren ser evaluados para interpretar la historia de los cambios ambientales de una manera más acertada (e.g. Valero-Garcés et al., 1999; Sáez et al., 2007). Los procesos volcánicos y tectónicos pueden influir en la sedimentación lacustre al modificar la forma y estructura de la cuenca por emplazamiento de edificios volcánicos y sus productos asociados (coladas de lava y depósitos piroclásticos), por el colapso de los mismos y por el tectonismo. Así mismo, la actividad volcánica ejerce un control en el suministro de materiales no consolidados que son fácilmente removidos a la cuenca, en el desarrollo de incendios en el entorno y en la química del agua por actividad hidrotermal y por el depósito directo de sus productos. Todos estos fenómenos pueden tener diferentes grados de impacto en los ecosistemas lacustres y terrestres.

La subcuenca de Chalco, al SE de la cuenca de México, se encuentra en una región caracterizada por la existencia de intensos y activos procesos volcánicos y tectónicos. El campo volcánico de la Sierra Chichinautzin, que forma el límite $\mathrm{S}$ de Chalco, contiene al menos 220 volcanes y productos asociados cuya edad es menor a $0.7 \mathrm{Ma}$ (Bloomfield, 1975; Martin del Pozzo, 1982; Lugo Hubp, 1984); aunque también han sido fechados depósitos con edades entre 0.09 y $1.2 \mathrm{Ma}$ (Arce et al., 2013). Entre los más jóvenes, al menos 14 conos tienen una edad menor a 25000 años (Siebe et al., 2004). Por otra parte, la actividad volcánica de los últimos miles de años de estructuras más distantes, como la Sierra Nevada y el Nevado de Toluca, ha incluido erupciones plinianas que originaron la dispersión y el depósito de piroclastos en amplias regiones (Arce et al., 2005, 2013; Arana-Salinas et al., 2010; Rueda et al., 2013), algunos de los cuales han sido reconocidos en la cuenca de Chalco. La distribución espacial de las estructuras volcánicas está controlada por debilidades corticales, reconocidas tanto en la alineación de los edificios volcánicos (e.g. Fries, 1962; Cserna et al., 1988), como en los análisis geofísicos (e.g. Vázquez-Sánchez y Jaimes-Palomera, 1989).

En este escenario, el registro sedimentario del lago de Chalco ofrece una oportunidad tanto para evaluar el impacto del volcanismo en la sedimentación lacustre, como para fortalecer el desarrollo de una tefracronología para la región.

Aun cuando existe información sobre la estratigrafía general de los sedimentos lacustres de la cuenca de Chalco a partir de excavaciones para estudios arqueológicos (e.g. Lorenzo y Mirambell, 1989), de la perforación de núcleos para estudios paleoclimáticos y paleomagnéticos (Ortega Guerrero, 1992; Lozano-García et al., 1993; Ortega-Guerrero et al., 2000; Sosa Nájera, 2001; Herrera Hernández, 2011; Correa-Metrio et al., 2013), y de registros 


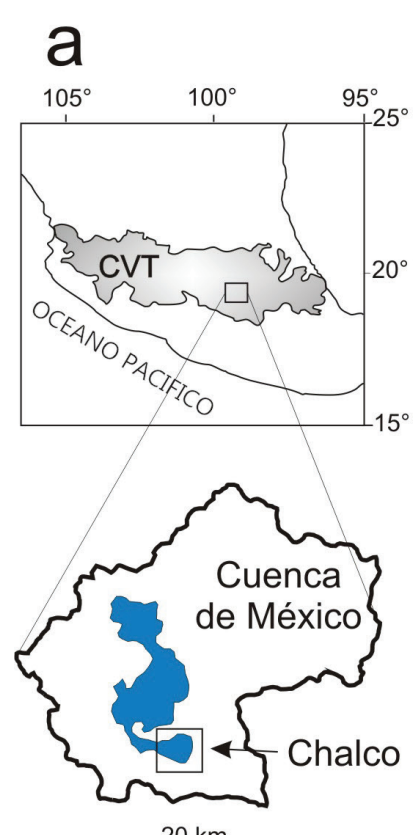

$20 \mathrm{~km}$

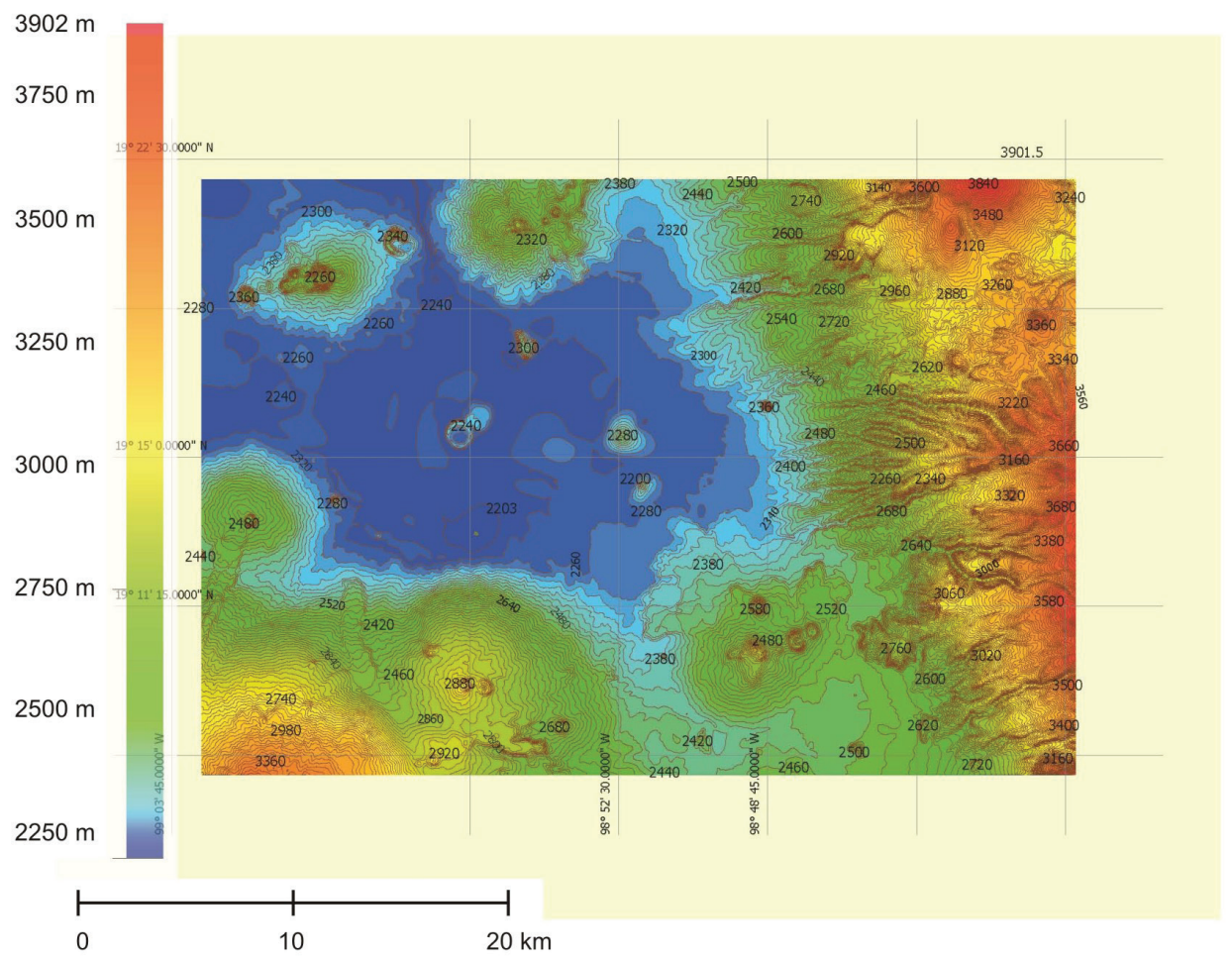

C

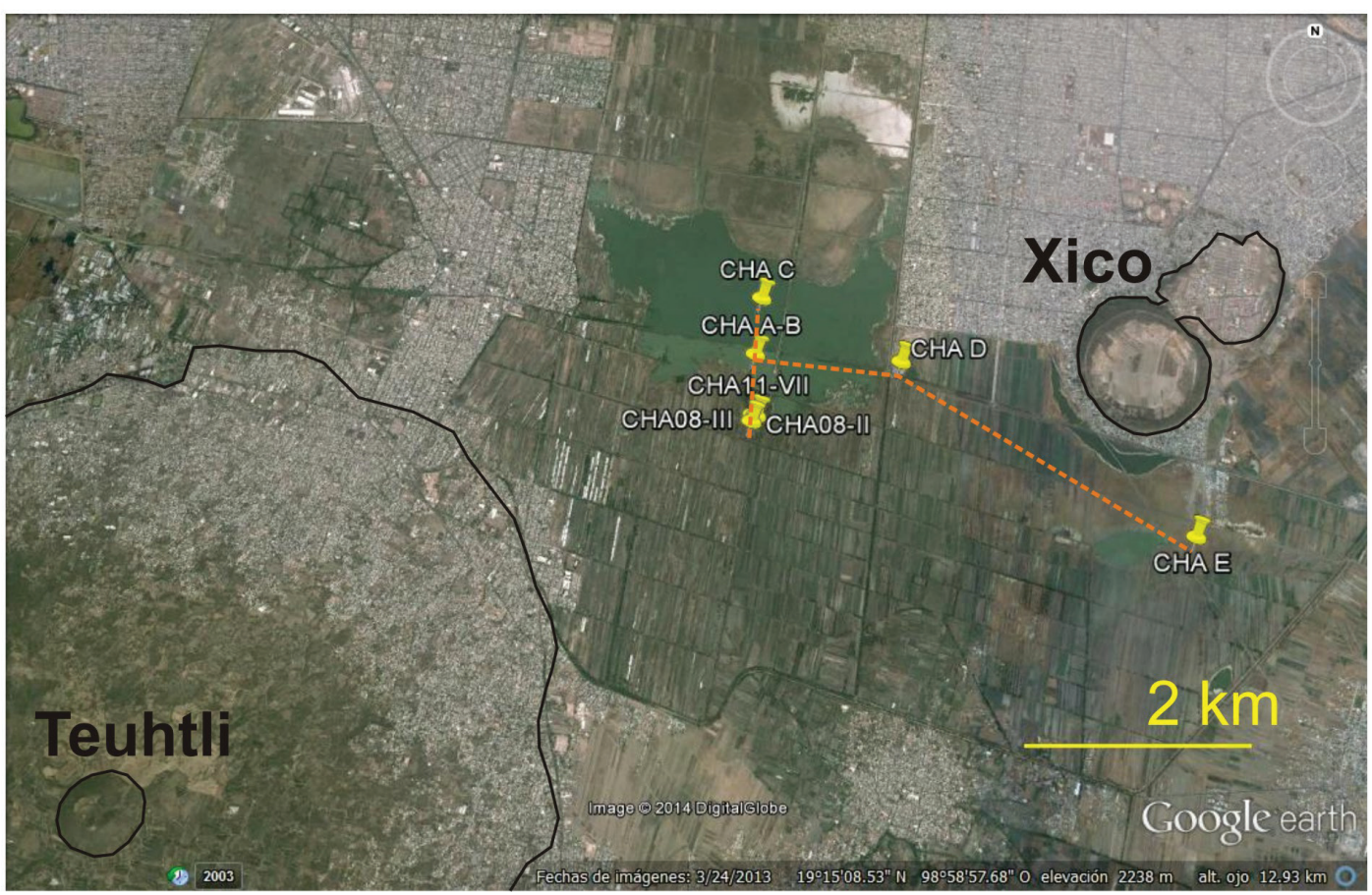

Figura 1. Localización de la cuenca de Chalco. a) Extensión del Cinturón Volcánico Transmexicano (CVT), y ubicación de la cuenca de México. El área azul representa la extensión máxima del sistema lacustre desarrollado en la cuenca, cuyo extremo SE fue ocupado por el lago de Chalco. b) Modelo de elevación de la cuenca de Chalco con algunas de las principales estructuras volcánicas mencionadas en este trabajo. La máxima extensión de los depósitos lacustres está representada por la cota 2300. c) Imagen de Google Earth con el detalle de la ubicación de los núcleos colectados. Las líneas naranjas indican la localización de los sondeos y los transectos de la figura 6. 
de pozos de agua (e.g. Ortiz-Zamora, 2007), no se han establecido modelos de facies detallados ni se conoce la distribución lateral de las mismas.

En este trabajo establecemos la sucesión estratigráfica representativa de los ca. $26.7 \mathrm{~m}$ superiores de los depósitos lacustres en Chalco. La integración de análisis estratigráficos y sedimentológicos de secuencias sedimentarias continuas, obtenidas en diversas etapas de perforación de núcleos para análisis paleoclimáticos, permitió elaborar un modelo de la distribución lateral de las facies sedimentarias y una reconstrucción de la arquitectura de los sedimentos lacustres. En esta reconstrucción, se evalúa el impacto de la actividad volcánica en el sistema lacustre.

\section{Ubicación y características geológicas}

La cuenca de Chalco $\left(19^{\circ} 15^{\prime} \mathrm{N}, 98^{\circ} 58^{\prime} \mathrm{W}, 2230\right.$ $\mathrm{m}$ snm), tiene un área aproximada de $1100 \mathrm{~km}^{2}$, de los cuales $c a .240 \mathrm{~km}^{2}$ corresponden a la planicie lacustre. Está limitada al $\mathrm{N}$ por los domos volcánicos de la Sierra de Santa Catarina, al E por la Sierra Nevada, formada por los estratovolcanes Popocatépetl, Iztaccíhuatl, Telapón y Tláloc, al $\mathrm{S}$ por el campo volcánico monogenético de la Sierra Chichinautzin, y al $\mathrm{W}$ por la divisoria por la que corre la avenida México-Tulyehualco, entre el cerro de la Estrella y el volcán Teuhtli, que la separa de la subcuenca de Xochimilco (Figura 1b).

La cuenca ocupa un graben ENE-WSW, cuyas fallas normales limitantes coinciden al N con la Sierra Santa Catarina y al $\mathrm{S}$ con un lineamiento paralelo entre el volcán Teuhtli y Topilejo (Vázquez-Sánchez y Jaimes-Palomera, 1989; Rodríguez-Chávez, 2003). En este graben ha sido reconocido un alto estructural de orientación NE-SW, que coincide con el alineamiento de los volcanes Xico y Tlapacoya, y que dividen al graben en dos cuencas E y W (Urrutia-Fucugauchi y Chávez-Segura, 1991; Campos Enríquez et al., 1997).

El sistema lacustre ha experimentado variaciones en su profundidad y extensión a lo largo de su historia (e.g. Iglesias, 1902; Caballero-Miranda, 1995), y en la actualidad está reducido a un lago perenne en forma de $\mathrm{C}$ invertida de 1 a $2 \mathrm{~m}$ de profundidad.

\section{Métodos}

La estratigrafía de la cuenca de Chalco se ha analizado a través de la obtención de núcleos con recuperación casi continua de sedimentos. Esta recuperación de núcleos se llevó a cabo en dos etapas principales. En 1988-1989 se recuperaron cuatro secuencias (núcleos CHA-B, CHA-C, CHA-D y CHA-E), de longitudes entre 8 y 26 m y diámetros entre 5 y $8 \mathrm{~cm}$. Los tres primeros fueron colectados utilizando un sistema de pistón tipo Livingston modificado.
El núcleo CHA-E fue recuperado utilizando un barril tipo Shelby de 4" de diámetro. Posteriormente, en la segunda etapa de perforación entre 2008 y 2011, se colectaron los núcleos CHA08-II, y CHA11-VII con el sistema Livingston, cuyas longitudes fueron 26.7 y $18 \mathrm{~m}$, respectivamente, así como el núcleo CHA08-III con el sistema Shelby, de 90 $\mathrm{m}$, del cual sólo incluimos datos de un segmento entre 16 y $26.7 \mathrm{~m}$ de profundidad. El núcleo CHA08-II presenta dos intervalos sin recuperación, debido a problemas durante la perforación causados por la presencia de horizontes de cenizas de gran espesor. Por ello, se colectó el núcleo CHA11-VII a una distancia menor de $10 \mathrm{~m}$ del sitio del CHA08-II, sin embargo, sólo se recuperó el intervalo faltante entre 12.74 y $18.00 \mathrm{~m}$ de profundidad.

Todos estos núcleos fueron colectados en porciones secas de la planicie lacustre, aunque actualmente el sitio del núcleo CHA-C se encuentra cubierto por el cuerpo de agua moderno (Figura 1c).

En los núcleos colectados se han llevado a cabo diversos análisis. En el núcleo CHA-B, el contenido de materia orgánica fue estimado a partir de la pérdida por calcinación (PPC) a $550{ }^{\circ} \mathrm{C}$ durante dos horas, en muestras colectadas cada $10 \mathrm{~cm}$ (Caballero y Ortega Guerrero, 1998). En 43 muestras de este núcleo se llevó a cabo el análisis de tamaño de partícula utilizando un analizador laser Coulter. Para ello, las muestras fueron cribadas en una malla de $500 \mu \mathrm{m}$ para remover los restos orgánicos mayores, y dispersadas en baño ultrasónico añadiendo unas gotas de amonia para evitar la floculación. El análisis del contenido de diatomeas de este núcleo fue elaborado por Caballero-Miranda (1995) y publicado posteriormente (Caballero y Ortega Guerrero, 1998).

La susceptibilidad magnética (SM) es el único parámetro que se ha medido en todos los núcleos. En aquellos de la etapa 1988-1989, se colectaron muestras individuales de manera continua cada $2 \mathrm{~cm}$, en cubos de acrílico de $2 \mathrm{~cm}$ de sección, y la SM fue medida en un sistema Bartington MS2. Una vez colectados los núcleos de la etapa 2008-2011 (CHA08-II, CHA08-III y CHA11-VII), éstos fueron enviados al Limnological Research Center (University of Minnesota) para su documentación. Los núcleos fueron seccionados longitudinalmente a la mitad, en una de las cuales se colectaron imágenes digitales de alta resolución con un sistema fotográfico DMT CoreScan. La SM fue medida en un sensor Bartington MS2-E cada $1 \mathrm{~cm}$, y se expresa en unidades adimensionales SI.

Las facies sedimentarias fueron definidas en los núcleos de la etapa 2008-2011 a partir de observaciones visuales y al microscopio en frotis, siguiendo la metodología descrita por Schnurrenberger y colaboradores (2003). La cronología utilizada en este trabajo fue obtenida considerando la edad de las tefras marcadoras reconocidas y fechadas por ${ }^{14} \mathrm{C}$ AMS para la región, así como las edades de ${ }^{14} \mathrm{C}$ obtenidas en sedimento total por el método radiométrico en 7 muestras del núcleo CHA-B, y en 8 muestras del CHA-D. (Ortega 
Guerrero, 1992; Caballero y Ortega Guerrero, 1998). Las edades obtenidas fueron calibradas utilizando la base de datos de Reimer y colaboradores (2013).

\section{Resultados}

\subsection{Facies sedimentarias}

Se identificaron trece facies en los núcleos recuperados en 2008 - 2011, a partir de las observaciones y los parámetros analizados. Las facies sedimentarias descritas se han agrupado en tres clases principales, de acuerdo a sus componentes más abundantes: facies clásticas, facies volcaniclásticas y facies biogénicas (Tabla 1; Figura 2). Las facies clásticas, diferenciadas en el color, son las más abundantes e incluyen sedimentos limosos con cantidades variables de arcilla y arena, compuestos de feldespatos, cuarzo, anfíboles y minerales arcillosos. La textura de los sedimentos varía de masiva, bandeada a laminada (2 a $10 \mathrm{~mm}$ de espesor). Contienen proporciones variables de componentes biogénicos tales como gasterópodos, ostrácodos, diatomeas, restos de tejido herbáceo y leñoso, y partículas de carbón (facies 1 a 10). Estos sedimentos son derivados mayormente del intemperismo y la erosión por corrientes fluviales superficiales y deflación de rocas, depósitos volcaniclásticos y suelos expuestos en la cuenca, que depositan y acumulan estos materiales en el lago. Existen en cantidades menores minerales autígenos, como pirita, calcita y estruvita (Pi et al., 2010). Las facies volcaniclásticas (facies 11), particularmente abundantes en los $6 \mathrm{~m}$ superiores, incluyen depósitos de caída (tefras) que han sido reconocidas y descritas anteriormente (ver referencias en Tabla 1), y depósitos volcaniclásticos retrabajados. Estos depósitos suman 18 capas individuales que varían de 0.5 a $106 \mathrm{~cm}$ de espesor, aunque también se encuentran componentes volcaniclásticos diseminados en sedimentos lacustres en secciones de 10 a $110 \mathrm{~cm}$ de espesor. Incluyen depósitos de lapilli de pómez y ceniza, masivos a bandeados (Figura 2, facies 11). Los depósitos identificados de erupciones documentadas son los de la Pómez Toluca Superior, procedente del Nevado de Toluca (Bloomfield y Valastro, 1977; Ortega-Guerrero y Newton, 1998; Arce et al., 2003, 2005), y la Pómez Tutti Frutti del Popocatépetl (Siebe et al., 1996; Siebe y Macías, 2004; Espinasa-Pereña y Martin del Pozzo, 2006). Así mismo, se reconoce un depósito compuesto de bandas de ceniza media que alternan con bandas de sedimentos lacustres con ceniza fina, denominado informalmente Gran Ceniza Basáltica (Mooser y González Rul, 1961) o Tláhuac (Ortega-Guerrero y Newton, 1998), cuyo probable origen se discute posteriormente. Las facies biogénicas incluyen ooze de diatomeas (facies 12), en estratos masivos de $20 \mathrm{~cm}$ de espesor, a láminas menores a $0.5 \mathrm{~cm}$ de espesor incluidas en facies clásticas, así como ooze de ostrácodos (facies 13), que forman láminas discretas de $<1 \mathrm{~cm}$ de espesor.
La correlación entre los núcleos se llevó a cabo a partir de los perfiles de susceptibilidad magnética (SM), y con la identificación de los principales depósitos volcaniclásticos. Las 13 facies sedimentarias se agrupan en tres unidades litoestratigráficas, cuya profundidad está referida al núcleo CHA11-VII.

Unidad 1. $(0.3-6.55 \mathrm{~m})$

Corresponde a la parte superior de los depósitos lacustres y está cubierta por, al menos, $30 \mathrm{~cm}$ de material altamente perturbado por las actividades agrícolas y por la deflación. La unidad está compuesta por las facies clásticas 3, 4.a, 4.b y 5 (Figura 3). Consiste en limo y limo arenoso con proporción variable de arcilla entre 5 y $35 \%$ (media $15 \%$ ) (Figura 4). En ella se encuentran seis depósitos volcaniclásticos que forman capas discretas bien definidas, así como acumulaciones de lapilli de pómez, algunos de ellos intensamente alterados, definidos como la facies 11.2. Estos fragmentos de pómez se encuentran diseminados o formando bandas de $1-3 \mathrm{~cm}$ de espesor que presentan gradación inversa. Entre los depósitos volcaniclásticos de esta unidad se encuentran los de la Pómez Toluca Superior (PTS) y la Pómez Tutti Frutti (PTF), con la asociada Pómez Gris (Tabla 1). Los depósitos volcaniclásticos en esta unidad representan el $18 \%$ del espesor. Los valores de PPC son variables, pero alcanzan los valores más altos de la secuencia, entre 2 y $65 \%$ (media $29 \%$ ). La SM correspondiente a las facies clásticas es, en general, menor a $10 \times 10^{-6} \mathrm{SI}$, y los máximos corresponden a depósitos volcaniclásticos (Figura 4).

Unidad 2. $(6.55-9.15 \mathrm{~m})$

Está caracterizada por el dominio de limo arcilloso pardo grisáceo masivo a tenuemente laminado de las facies clásticas 9.a y 9.b y, en menor proporción, por la facies 4.b (Figura 2). Constituye la unidad con el mayor contenido de minerales arcillosos (hasta $32 \%$ ) (Figura 4). El contacto con la unidad superior es transicional, a lo largo de $10 \mathrm{~cm}$ de espesor. Una ceniza gris clara muy fina de $2 \mathrm{~cm}$ de espesor es el depósito basal de esta unidad. El contacto de esta ceniza con los sedimentos suprayacentes es gradual (Figura 2, facies 9a). En esta unidad los depósitos volcaniclásticos son escasos y representan tan sólo el $2.5 \%$ del espesor. Presenta dos horizontes de depósitos volcaniclásticos de ceniza de 2 $\mathrm{cm}$ de espesor. El contenido de materia orgánica estimado por PPC varía entre 11 y $23 \%$ (media $16.6 \%$ ). No hay presencia de ostrácodos ni gasterópodos. La susceptibilidad magnética correspondiente a las facies clásticas varía entre 10 y $30 \times 10^{-6}$ SI y los máximos corresponden a depósitos volcaniclásticos (Figura 4).

Unidad 3. $(9.15-$ ca. $26 \mathrm{~m})$

Esta unidad es la de mayor espesor. Incluye sedimentos dominados por limo, arcilloso o arenoso localmente, pardo, pardo grisáceo y pardo amarillo, bandeados (1 a 4 $\mathrm{cm}$ de espesor) a laminados (2 a $10 \mathrm{~mm}$ de espesor), que 
Tabla 1. Facies de los sedimentos del lago de Chalco.

\begin{tabular}{|c|c|c|c|}
\hline Facies & Rasgos sedimentológicos & & Ambiente de depósito \\
\hline \multirow[t]{6}{*}{ Clásticas } & $\begin{array}{l}\text { 1. Arena fina limosa negra }(10 \mathrm{YR} 2 / 1) \text {, } \\
\text { masiva a bandeada, en estratos de } 2-10 \\
\mathrm{~cm} \text { espesor. Cantidades variables de } \\
\text { componentes biogénicos: diatomeas, } \\
\text { ostrácodos, restos herbáceos, semillas. } \\
\text { Susceptibilidad magnética (SM) entre } 20 \\
\text { a } 100(\mathrm{~m}=40) 10^{-6} \mathrm{SI} \text {, pérdida por } \\
\text { calcinación }(\mathrm{PPC})<2 \% \text {. } \\
\text { 2. Limo arenoso a arena limosa pardo } \\
\text { gris }(2.5 \mathrm{Y} 5 / 2) \text { a gris muy obscuro } \\
(10 \mathrm{YR} 3 / 1) \text { masiva, con tenues bandas }< \\
2 \text { cm espesor de limo arenoso pardo } \\
\text { rojizo obscuro (5YR } 3 / 4) \text {. Presenta } \\
\text { bandas } 1 \mathrm{~cm} \text { espesor de arena gruesa } \\
\text { limosa gris muy obscuro }(10 \mathrm{YR} 3 / 1) \text {. } \\
\text { Abundantes componentes biogénicos: } \\
\text { ostrácodos, diatomeas y fragmentos } \\
\text { herbáceos. Contactos no paralelos, } \\
\text { irregulares y difusos. SM } 2 \text { a } 40(\mathrm{~m}= \\
11.6) 10^{-6} \mathrm{SI} \text {, PPC } 15-20 \% \text {. }\end{array}$ & & $\begin{array}{l}\text { Facies } 1 \text { y } 2 . \text { Lago somero, en } \\
\text { contracción, con influencia de } \\
\text { descarga de arroyos. }\end{array}$ \\
\hline & $\begin{array}{l}\text { 3. Limo arenoso con cantidades menores } \\
\text { de arcilla }(<10 \%) \text {, negro }(10 \mathrm{YR} 2 / 1) \text {, } \\
\text { gris obscuro }(10 \mathrm{YR} 4 / 1) \text { a pardo amarillo } \\
\text { obscuro }(10 \mathrm{YR} 3 / 4) \text {, bandeado a } \\
\text { tenuemente laminado, con fragmentos de } \\
\text { pómez de la facies } 11.2 \text {. Abundan restos } \\
\text { de ostrácodos y existen restos de raíces y } \\
\text { otros fragmentos leñosos. SM } 1 \text { a } 35(\mathrm{~m} \\
=6.2) 10^{-6} \mathrm{SI} \text {, PPC } 25-35 \% \text {. }\end{array}$ & & $\begin{array}{l}\text { Lago somero. Puede representar } \\
\text { depósitos distales de eventos de } \\
\text { flujos de detritos. }\end{array}$ \\
\hline & $\begin{array}{l}\text { 4. Limo arenoso con cantidades menores } \\
\text { de arcilla }(<10 \%) \text {, negro }(10 \text { YR } 2 / 1) \text { a } \\
\text { pardo gris obscuro }(10 \text { YR } 4 / 2) \text {, masivo a } \\
\text { laminado. Abundantes componentes } \\
\text { biogénicos: materia orgánica amorfa, } \\
\text { restos de organismos lacustres y } \\
\text { terrestres: diatomeas, ostrácodos, carbón, } \\
\text { raíces y otros fragmentos herbáceos y } \\
\text { leñosos. SM } 1 \text { a } 20(\mathrm{~m}=5.6) 10^{-6} \mathrm{SI} \text {, } \\
\text { PPC } 10-65 \% \text {. }\end{array}$ & $\begin{array}{l}\text { Subfacies 4.a: Intervalos } \\
\text { decimétricos masivos de } \\
1 \text { a } 7 \mathrm{dm} \text { espesor. } \\
\text { Contactos rectos. } \\
\text { Subfacies 4.b: } \\
\text { Intervalos decimétricos } \\
\text { bandeados a tenuemente } \\
\text { laminados. Láminas } \\
\text { negras a pardo gris } \\
\text { obscuro discontinuas, } \\
\text { con contactos difusos e } \\
\text { irregulares. }\end{array}$ & $\begin{array}{l}\text { Facies } 4 \text { a } 7 \text {. Lago somero, con } \\
\text { poca influencia de sistemas } \\
\text { lóticos. Facies perimetrales con } \\
\text { fases variables de crecimiento de } \\
\text { vegetación. }\end{array}$ \\
\hline & $\begin{array}{l}\text { 5. Limo arenoso negro }(10 \mathrm{YR} 2 / 1) \text { a } \\
\text { pardo obscuro }(10 \mathrm{YR} 3 / 3) \text { con } \\
\text { cantidades menores de arcilla }(<10 \%) \text {, } \\
\text { masivo, con abundantes componentes } \\
\text { biogénicos: ostrácodos, gasterópodos y } \\
\text { fragmentos leñosos; con concreciones de } \\
\text { carbonato. SM } 8 \text { a } 100(\mathrm{~m}=29) 10^{-6} \mathrm{SI} \text {, } \\
\text { PPC } 15-22 \% \text {. }\end{array}$ & & \\
\hline & $\begin{array}{l}\text { 6. Limo arenoso pardo oliva }(2.5 \mathrm{Y} 4 / 3) \text {, } \\
\text { masivo a tenuemente laminado a } \\
\text { bandeado. Láminas }(1 \mathrm{~cm}) \text { y bandas }(1-2 \\
\mathrm{cm}) \text { pardo gris muy obscuro }(2.5 \mathrm{Y} 3 / 2) \text {. } \\
\text { Abundantes componentes biogénicos: } \\
\text { diatomeas, ostrácodos, carbón. SM } 2 \text { a } \\
14(\mathrm{~m}=14.6) 10^{-6} \mathrm{SI} \text { PPC } 10-32 \% \text {. }\end{array}$ & & \\
\hline & $\begin{array}{l}\text { 7. Limo arenoso pardo grisáceo ( } 10 \mathrm{YR} \\
3 / 2 \text { ) a pardo rojizo }(5 \mathrm{YR} 3 / 2) \text {, en }\end{array}$ & & \\
\hline
\end{tabular}


Tabla 1. Facies de los sedimentos del lago de Chalco (Continuación).

intervalos masivos de $<15 \mathrm{~cm}$ espesor, y

bandas $1-3 \mathrm{~cm}$ espesor. Contactos

irregulares, difusos. Escasos

componentes biogénicos: ostrácodos, diatomeas, restos herbáceos y carbón. SM 2 a $55(\mathrm{~m}=38.6) 10^{-6}$ SI, PPC $2-18$ $\%$.

8. Limo a limo arenoso pardo gris $(2.5 \mathrm{Y}$

$5 / 2)$, con intervalos decimétricos $(10-60$ $\mathrm{cm})$ masivos, e intervalos con bandas (2 $-20 \mathrm{~cm}$ ) de limo de color variable: pardo obscuro (10YR 3/3), gris obscuro (10YR 4/1), pardo amarillo obscuro (10YR 3/4), pardo rojizo obscuro (5YR3/4) a gris claro (2.5Y 7/2). Contactos nítidos e irregulares. La arena se encuentra tanto diseminada en intervalos ocasionales de $<15 \mathrm{~cm}$ espesor, como en bandas irregulares de $1-2 \mathrm{~cm}$ espesor.

Abundantes componentes biogénicos: ostrácodos, diatomeas, espículas. SM 2 a $14(\mathrm{~m}=8.1) 10^{-6} \mathrm{SI}$, PPC $8-20 \%$.

9. Limo arcilloso pardo grisáceo muy obscuro (10YR 3/2), con arena lítica, masivo a tenuamente laminado, contactos rectos a transicionales y difusos. SM 2 a $70(\mathrm{~m}=15.7) 10^{-6} \mathrm{SI}$, PPC $10-25 \%$, excepcionalmente a 64 $\%$.

10. Limo arcilloso pardo gris obscuro (2.5Y 4/2) con láminas $<0.8 \mathrm{~cm} \mathrm{y}$ bandas $2-3 \mathrm{~cm}$ de limo arcilloso amarillo pálido (2.5Y 8/2), discontinuas, y ocasionales láminas $<1 \mathrm{~cm}$ de arena negra media. Estratificación no paralela en la parte superior (40 $\mathrm{cm}$ espesor). Contiene lentes y cuñas $<10 \mathrm{~cm}$ espesor de la ceniza que sobreyace a esta facies. Contactos irregulares a rectos, difusos. Escasos restos de ostrácodos. SM 2 a 14 $(\mathrm{m}=5.7) 10^{-6} \mathrm{SI}, \mathrm{PPC}$ no disponible.
Lago somero, con poca influencia de sistemas lóticos, y con eventos de depósito de piroclastos de caída.

Subfacies 9.a. Intervalos decimétricos con láminas tenues, pardas (10YR 4/2) a gris muy obscuro (10YR 3/1),

discontinuas, con cantidades variables de arena media lítica y restos de carbón. Contactos transicionales y difusos.

Subfacies 9.b. Intervalos masivos de 10 a $20 \mathrm{~cm}$ espesor, con cantidades variables de arena media lítica y restos de carbón.

Contactos rectos.
Lago somero.

Lago relativamente profundo. La característica no paralela de la estratificación y los lentes y cuñas de ceniza observados, son debidas a la deformación por carga ejercida por el depósito de la tefra sobreyaciente y a la inyección del mismo material en los depósitos lacustres.

\begin{tabular}{ll}
\hline Volcani- & 11.1. PTF Lapilli amarillo pálido (2.5YR \\
clásticas & 8/3) masivo, compuesto de fragmentos \\
& angulares de pómez de $0.5-2 \mathrm{~cm}$ \\
& diámetro, sin matriz, y numerosos \\
& fragmentos líticos de diversa \\
& composición. El espesor del depósito \\
& varía de 35 a $38 \mathrm{~cm}$. SM 3 a $153(\mathrm{~m}=$
\end{tabular}

23.2) $10^{-6} \mathrm{SI}$. Se encuentra asociada una 
Tabla 1. Facies de los sedimentos del lago de Chalco (Continuación).

ceniza gris (10YR 7/1) cuyo espesor

varía de 5 a $7 \mathrm{~cm}$. SM entre 20 a $162(\mathrm{~m}$

$=83.9$ ) $10^{-6}$ SI. Ambos depósitos se

encuentran separados por una capa de

limo de $<2 \mathrm{~cm}$ de espesor, excepto en el

núcleo CHA-C, en el que está ausente la capa de limo.

11.2 Lapilli de pómez amarillo pálido (2.5YR 8/3), de $2-5 \mathrm{~mm}$ diámetro, altamente intemperizado. Se encuentra como fragmentos de pómez tanto diseminados como formando bandas 1 $3 \mathrm{~cm}$ espesor, y con gradación inversa.

11.3. GCB Ceniza media negra (2.5Y $2.5 / 1$ ), en bandas $5-18 \mathrm{~cm}$ de espesor, intercaladas con bandas $1-1.5 \mathrm{~cm}$ de ceniza fina con limo gris (2.5Y 5/1).

Contactos rectos e irregulares, nítidos y difusos. El espesor máximo se encontró en el núcleo CHA11-VII, de $0.98 \mathrm{~m}$. SM 40 a $590(\mathrm{~m}=262) 10^{-6} \mathrm{SI}$.

11.4. Ceniza negra (2.5Y 2.5/1) a gris (10YR 5/1), con contenido variable de limo, masiva o estratificada, de $0.5-12 \mathrm{~cm}$ espesor. Cantidades variables de componentes biogénicos: diatomeas u ostrácodos.

11.5. PTS Ceniza fina gris (10YR 6/1). Contacto inferior recto y abrupto, contacto superior inclinado y transicional. El espesor del depósito varía de 12 a $14 \mathrm{~cm}$. SM 2 a $18(\mathrm{~m}=9.8) 10^{-6}$ SI.

\begin{tabular}{ll}
\hline Biogénicas & 12. Ooze de diatomeas. Presenta $>50 \%$ \\
& de testas de diatomeas con limo gris \\
& rosáceo $(7.5 \mathrm{YR} 7 / 2)$ a blanco $(7.5 \mathrm{YR}$ \\
& $8 / 1)$, laminado $(0.8-1 \mathrm{~cm})$ a bandeado \\
& $(1.2-3 \mathrm{~cm})$ en láminas y bandas difusas \\
& de 0.5 a $3 \mathrm{~cm}$ de espesor. Dominan \\
& especies de Fragilaria y Cocconeis. SM \\
& 3 a $13(\mathrm{~m}=8.4) 10^{-6} \mathrm{SI}$.
\end{tabular}

13. Ooze de ostrácodos. Presenta $>50 \%$ de valvas de ostrácodos bien preservadas con arena media a gruesa, en capas de 1 $-3 \mathrm{~cm}$ espesor. En la facies 11 abundan Heterocypris spp. y Candona spp. Comúnmente asociada a las facies 3, 4, $6,7,9$ y 10 .
Depósito de carga en suspensión y de caída de la atmósfera.

Conjunto de depósitos piroclásticos de caída y material retrabajado, originado probablemente por el volcán monogenético Teuhtli (Guilbaud et al., 2015). Conocida localmente como Gran ceniza basáltica (Mooser, 1967) o Tláhuac (Ortega y Newton, 1998).

Depósitos piroclásticos de caída y material retrabajado, de fuente desconocida, probablemente de volcanes monogenéticos del campo Chichinautzin y la sierra de Santa Catarina. La composición varía de dacita a andesita basáltica. Los picos de la susceptibilidad magnética corresponden mayormente a estos depósitos.

Depósito piroclástico de caída pliniano originado por el Nevado de Toluca, designado Pómez Toluca Superior (Bloomfield y Valastro, 1977; Macías et al., 1997; Arce et al., 2003).

\author{
Lago moderadamente profundo, \\ que en el núcleo CHA-B se \\ estima alcanzó $c a .3 \mathrm{~m}$ de \\ profundidad (Caballero y Ortega \\ Guerrero, 1998).
}

Lago somero, con sedimentación predominantemente endogénica. El excelente estado de preservación de los ostrácodos indica ambiente de baja energía. 


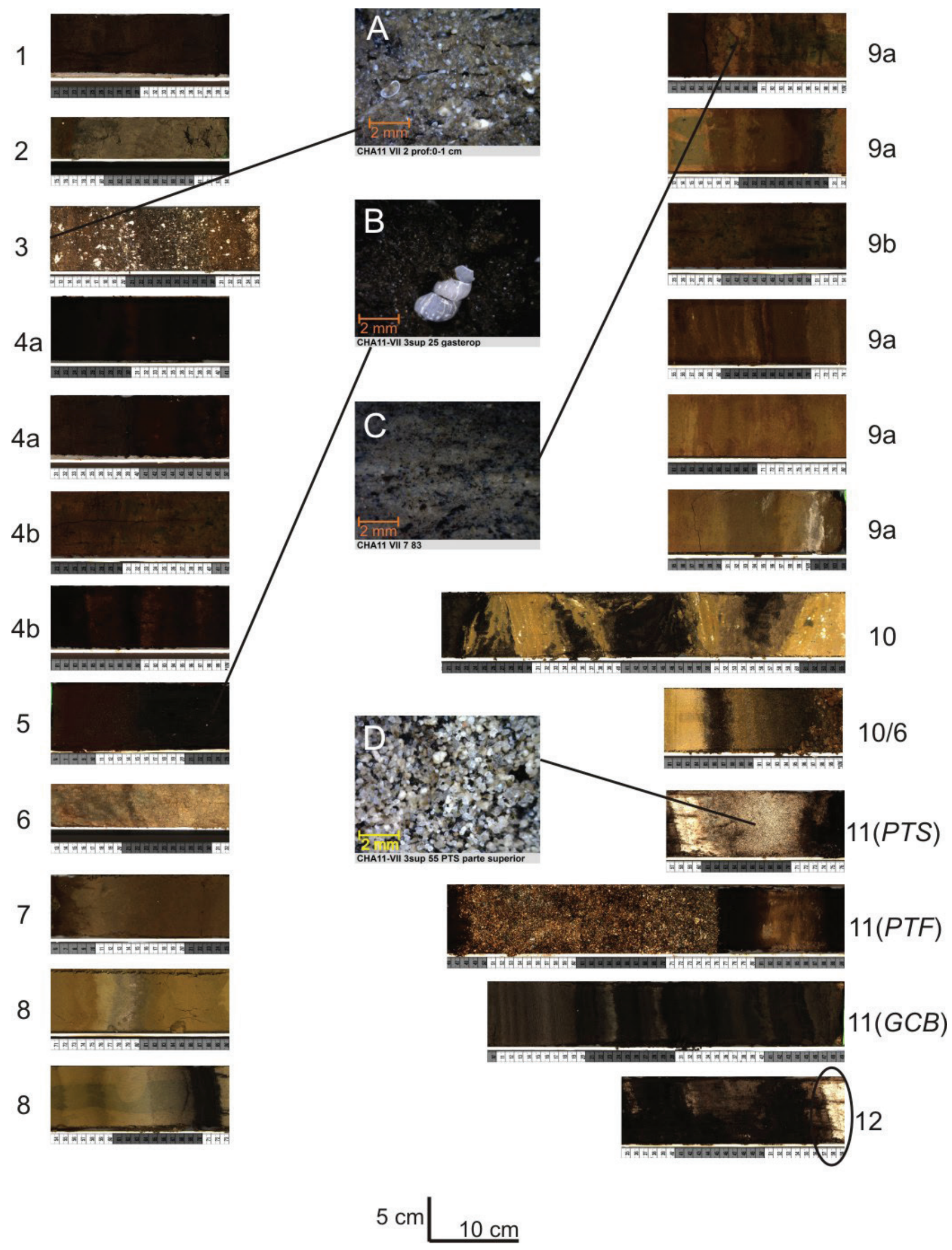

Figura 2. Imágenes de alta resolución de las secciones de sedimento correspondientes a 12 de las facies descritas en el núcleo CHA11-VII de la cuenca de Chalco (Tabla 1). A) Restos de ostrácodos de la facies 3. B) Restos de gasterópodos, ostrácodos, concreciones de carbonato y fragmentos leñosos en el limo arenoso de la facies 5. C) Láminas tenues y discontinuas, y abundantes fragmentos de carbón de la facies 9a. D) Ceniza fina de la Pómez Toluca Superior. 

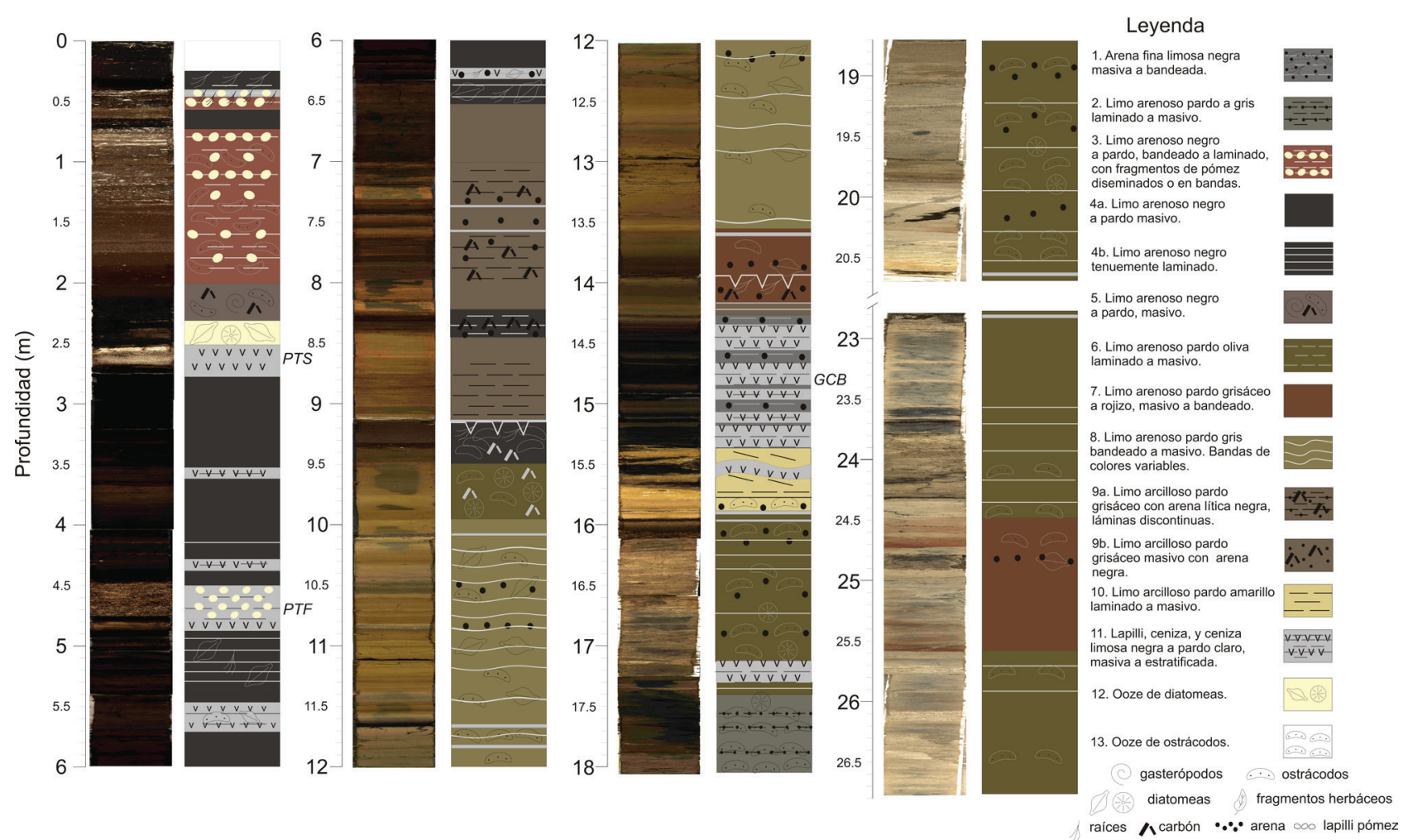

Figura 3. Columna estratigráfica compuesta de los núcleos CHA11-VII (0.30-18 m), y CHA08-II (18.60-26.7 m). A la izquierda, imágenes de alta resolución de los núcleos, obtenidas en un equipo DMT CoreScan. Se indica la posición de las tefras marcadoras Pómez Toluca Superior (PTS), Pómez Tutti Frutti $(P T F)$, y Gran Ceniza Basáltica $(G C B)$ o Tláhuac.

constituyen las facies 2 y 5 a 9 . Pese a que conserva la laminación y el bandeamiento en una extensa porción de la secuencia sedimentaria, los contactos frecuentemente son irregulares y no paralelos (Figura 2, facies 7 y 8). En la facies 7 (a 14 y $25 \mathrm{~m}$ de profundidad), existen contactos que sugieren la exposición subaérea del sedimento, el desarrollo de marcas de desecación e intemperismo. El contacto entre esta unidad y la ceniza basal de la unidad 2 es irregular y abrupto, probablemente erosivo. La presencia de ostrácodos es una de sus principales características, que localmente forman oozes de $2-4 \mathrm{~cm}$ de espesor. La cantidad de materia orgánica inferida por PPC varía entre 1 y $65 \%$ (media 15.2\%) (Figura 4). Contiene 10 capas de depósitos volcaniclásticos continuos compuestos por ceniza negra, cuyos espesores varían entre 2 y $15 \mathrm{~cm}$. Sin embargo, el más conspicuo de ellos el más conspicuo es el que corresponde a la llamada Gran Ceniza Basáltica (GCB) o Tláhuac. Este depósito está constituido por bandas de ceniza negra de 5 $18 \mathrm{~cm}$ espesor, intercaladas con bandas $1-1.5 \mathrm{~cm}$ de ceniza fina con limo gris. Debajo de esta secuencia, los sedimentos de la facies 10 están intercalados con cuñas y bandas irregulares de ceniza con las características texturales de la $G C B$ a lo largo de $40 \mathrm{~cm}$ (Figura 2, facies 10). Los depósitos volcaniclásticos en esta unidad constituyen el $16 \%$ del espesor. La susceptibilidad magnética correspondiente a las facies clásticas es en general menor a 10 x $10^{-6} \mathrm{SI}$ y los máximos corresponden a depósitos volcaniclásticos (Figura 4). En el núcleo CHA-B, la base de la $G C B$ se encuentra a $18.7 \mathrm{~m}$ de profundidad, en tanto que en el CHA11-VII lo está a $15.4 \mathrm{~m}$. En los núcleos CHA08-II y CHA11-VII, fueron colectados $11.3 \mathrm{~m}$ de sedimento debajo de la $G C B$. Asumiendo este espesor debajo de la $G C B$ en el núcleo CHA-B, el espesor total de la secuencia lacustre analizada es de $30 \mathrm{~m}$. Esta consideración se tomará en cuenta más adelante, cuando se discuta el modelo de edad.

\section{Discusión}

\subsection{Modelo de edad}

Las edades de ${ }^{14} \mathrm{C}$ de los núcleos CHA-B y CHA-D (Figura 5, Tabla 2), abarcan entre 5608 y $>34000$ cal A.P. (Ortega Guerrero, 1992; Caballero y Ortega Guerrero, 1998; Tabla 2). Dos excelentes marcadores estratigráficos de esta región cuya edad ha sido ampliamente documentada son los depósitos de pómez de caída originados por grandes erupciones plinianas, la Pómez Tutti Frutti $(P T F)$ y la Pómez Toluca Superior (PTS). La edad de estos depósitos corresponde a $17670 \mathrm{cal} \mathrm{A.P.} \mathrm{(Ortega-Guerrero} \mathrm{y} \mathrm{Newton,}$ 1998); y 12319 cal A.P. (García-Palomo et al., 2002; Arce et al., 2006), respectivamente. Esta última edad es cercana 


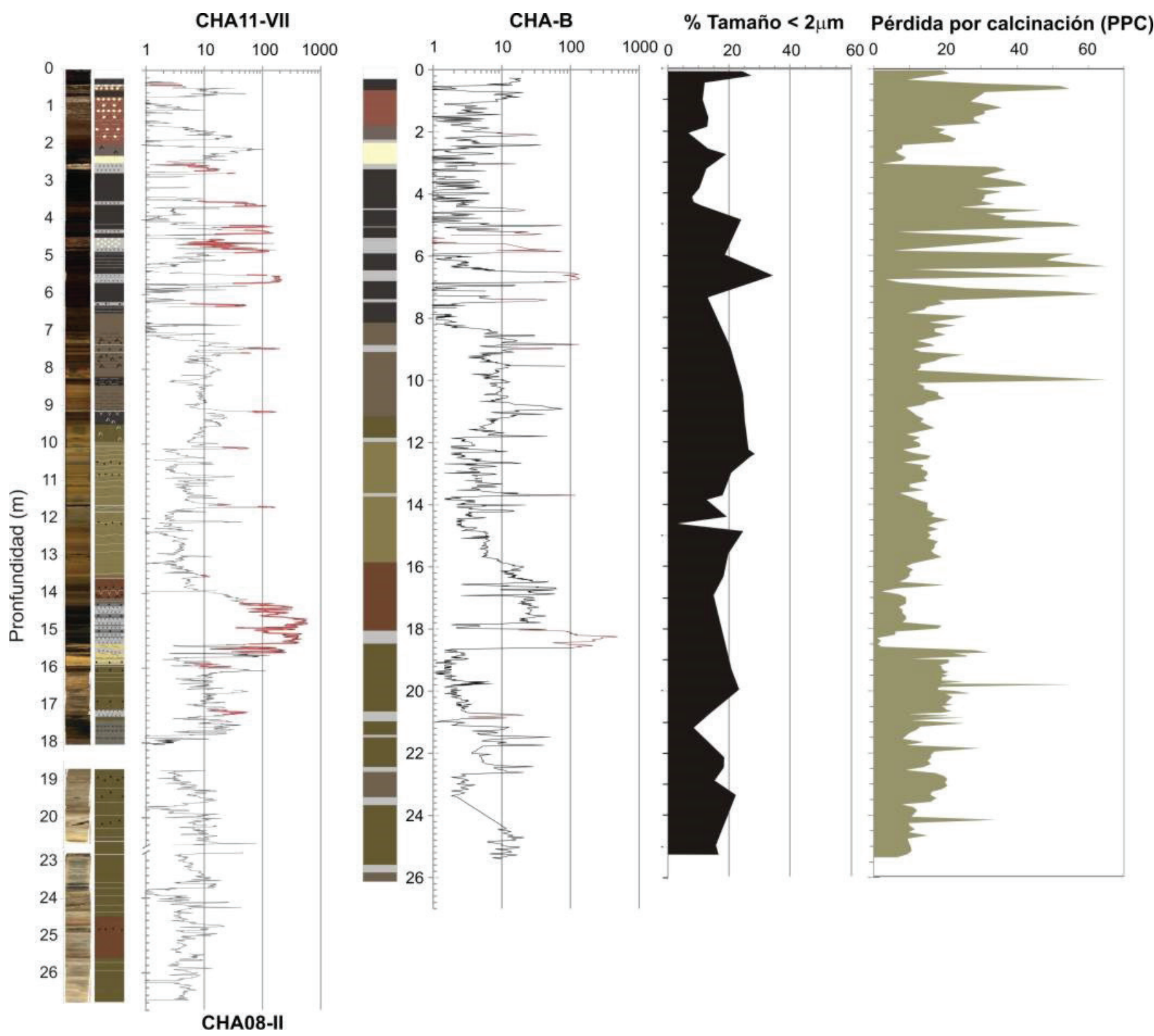

Figura 4. Estratigrafía y susceptibilidad magnética (SM) de la secuencia compuesta por los núcleos CHA11-VII y CHA08-II; así como estratigrafía, susceptibilidad magnética $(\mathrm{SM})$, porcentaje de la fracción arcilla $(<2 \mu \mathrm{m})$ y pérdida por calcinación $(\mathrm{PPC})$, del núcleo CHA-B. Las porciones en rojo en las curvas de SM corresponden a cenizas volcánicas.

a la edad obtenida en el núcleo CHA-B debajo de este depósito, a $2.55 \mathrm{~m}$ de profundidad.

Otros depósitos de caída reconocidos, aunque sin un control cronológico tan detallado como los anteriores, son la Gran Ceniza Basáltica (GCB), o Tláhuac, y la Pómez Ocre (PO) (Arana-Salinas et al., 2010). El sedimento 4 $\mathrm{cm}$ por arriba de la $G C B$ en el núcleo CHA-B fechado por radiocarbono arrojó una edad $>34000$ años A.P. (LozanoGarcía et al., 1993). En el sitio arqueológico de Tlapacoya (7.9 km al NE del núcleo CHA11-VII), un fragmento de madera debajo de la $G C B$ fue fechado en $33500+3200 /-$ 2300 años A.P. (40969 a $34673 \mathrm{cal} \mathrm{A.P.)} \mathrm{(Lambert,} \mathrm{1986).} \mathrm{En}$ un núcleo colectado en la cuenca de Texcoco, un horizonte $76 \mathrm{~cm}$ por arriba de la $G C B$ fue fechado por radiocarbono en 26135 años A.P. (29206 cal A.P.) (Lozano-García y Ortega-
Guerrero, 1998). Por otra parte, Mooser (1997) reporta una edad de 28600 años A.P. (30697 cal A.P.), obtenida en un fragmento de madera bajo la $G C B$, en una excavación al pie del Cerro de la Estrella. Aunque las edades de radiocarbono asociadas al depósito de la $G C B$ no son concluyentes, la edad de este depósito está constreñida aproximadamente entre $c a .27000$ y $41000 \mathrm{cal}$ A.P.

Las edades de las referidas tefras están en concordancia con las fechas obtenidas en los sedimentos lacustres. La extrapolación lineal de las edades del núcleo CHA-B indica que los sedimentos lacustres de los $26 \mathrm{~m}$ superiores alcanzan una edad de $c a .51000$ cal A.P. (Figura 5). La superficie de la cuenca de Chalco ha experimentado intensas actividades agrícolas en las últimas décadas, por lo que se considera que la cima de las secuencias sedimentarias sin 

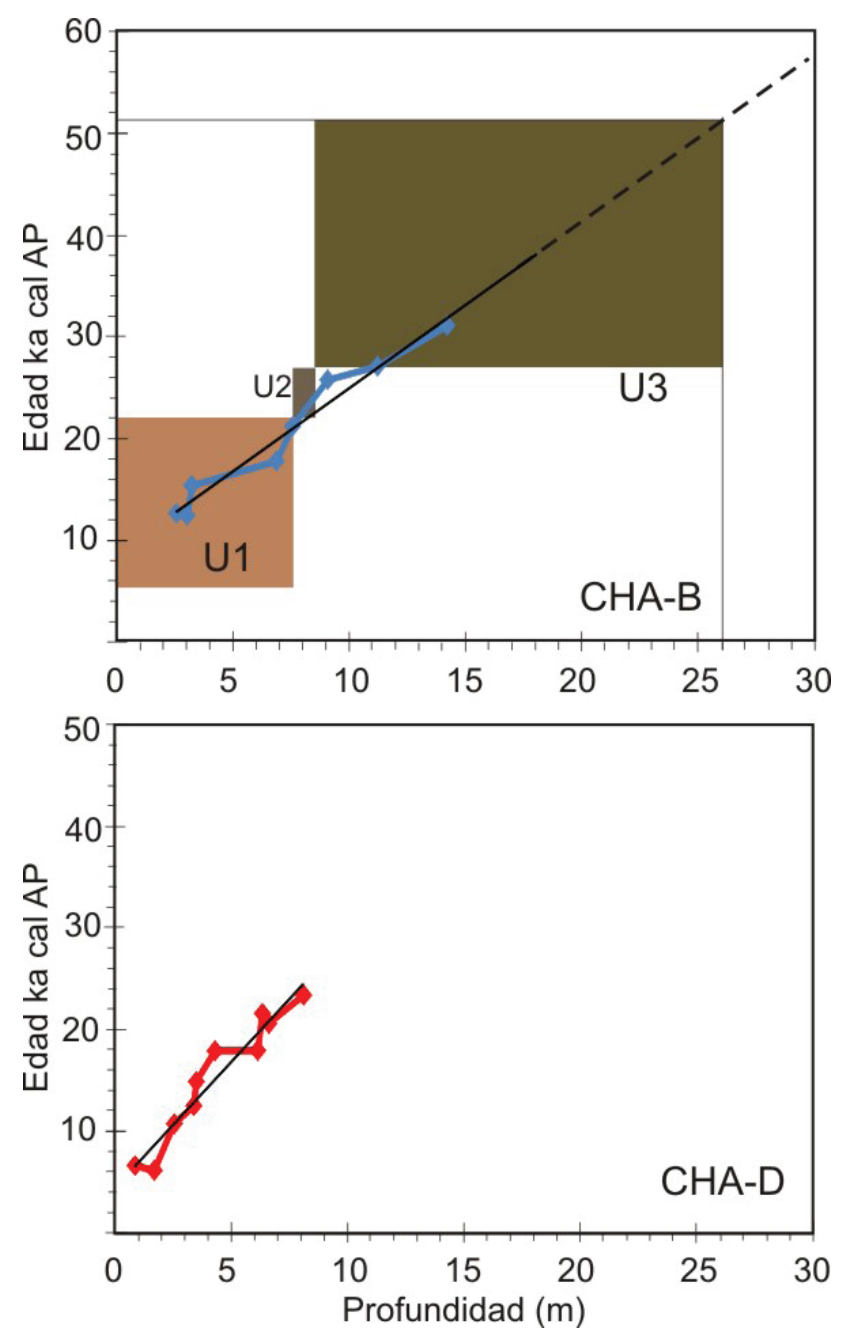

Figura 5. Modelos de edad, de acuerdo a las edades calibradas en miles de años AP, obtenidas para los núcleos CHA-B (línea azul) y CHA-D (línea roja), así como la edad de las tefras Pómez Tutti Frutti PTF y la Pómez Toluca Superior PTS (Tabla 2). Los ca. $26 \mathrm{~m}$ de la secuencia sedimentaria en CHA-B podrían abarcar los últimos ca. 51000.

perturbación o erosión tienen una edad entre 4000 a 5000 cal A.P. (Caballero y Ortega Guerrero, 1998). Las tasas de sedimentación, calculadas mediante una regresión lineal entre los horizontes fechados de los núcleos CHA-B y CHA-D, varían entre 0.21 y $0.80 \mathrm{~mm} / \mathrm{año}$. Con las edades disponibles en el núcleo CHA-B, el límite entre las unidades 3 y 2 se ubica en $c a$. 26500 cal A.P., y entre las unidades 2 y 1 en ca. 22000 cal A.P.

\subsection{Correlación entre núcleos y arquitectura} sedimentaria.

La correlación entre las diferentes secuencias colectadas en los núcleos se basa en criterios litoestratigráficos y sedimentológicos, es decir, en la identificación de la continuidad lateral de las facies y los límites entre las unidades, el reconocimiento de las tefras marcadoras de la
Tabla 2. Edades de radiocarbono de sedimentos del lago de Chalco y tefras marcadoras.

\begin{tabular}{|c|c|c|c|c|c|}
\hline Núcleo & $\begin{array}{l}\text { Profundidad } \\
\text { (m) }\end{array}$ & $\begin{array}{c}\text { Edad }{ }^{14} \mathrm{C} \\
( \pm 1 \sigma \text { años } \\
\text { A.P. })\end{array}$ & $\begin{array}{c}\text { Edad cal } \\
\mathrm{AP}^{*}\end{array}$ & Tefra & $\begin{array}{c}\text { Clave } \\
\text { laboratorio }\end{array}$ \\
\hline CHA-B & 2.55 & $10528 \pm 74$ & 12522 & & AA- 13340 \\
\hline CHA-B & 3.0 & $10445 \pm 74^{\mathrm{a}}$ & 12319 & PTS & n.d. \\
\hline CHA-B & 3.205 & $12800 \pm 90$ & 15280 & & WAT-2487 \\
\hline CHA-B & 6.85 & $14500^{\mathrm{b}} \pm 100$ & 17670 & PFT & \\
\hline CHA-B & 7.54 & $17450 \pm 170$ & 21091 & & WAT-2488 \\
\hline CHA-B & 9.05 & $21600 \pm 1,050$ & 25639 & & GX-16967 \\
\hline CHA-B & 11.2 & $22720 \pm 250$ & 26965 & & AA-17042 \\
\hline CHA-B & 14.2 & $26910 \pm 300$ & 30099 & & AA-17043 \\
\hline CHA-B & 18.0 & $>34000$ & & & GX-16968 \\
\hline CHA-D & 0.88 & $5725 \pm 175$ & 6579 & & GX-16970 \\
\hline CHA-D & 1.7 & $5330 \pm 235$ & 6085 & & GX-16966 \\
\hline CHA-D & 2.565 & $9395 \pm 255$ & 10614 & & GX-16969 \\
\hline CHA-D & 3.4 & $10445 \pm 74^{\mathrm{a}}$ & 12319 & PTS & n.d. \\
\hline CHA-D & 3.51 & $12520 \pm 135$ & 14683 & & GX-16965 \\
\hline CHA-D & 4.32 & $14610 \pm 470$ & 17640 & & GX-16972 \\
\hline CHA-D & 6.15 & $14500 \pm 100^{\mathrm{b}}$ & 17670 & $P F T$ & \\
\hline CHA-D & 6.35 & $17560 \pm 330$ & 21238 & & GX-16558 \\
\hline CHA-D & 6.625 & $16820 \pm 195$ & 20289 & & GX-16971 \\
\hline CHA-D & 8.13 & $19040 \pm 390$ & 23011 & & GX-16559 \\
\hline
\end{tabular}

*Base de datos usada INTCAL13 Reimer et al. (2013).

a Edad reportada para la Pómez Toluca Superior (PTS), García-Palomo et al. (2002) y Arce et al. (2003).

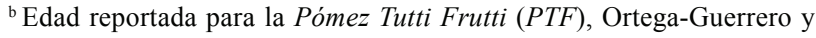
Newton (1998).

AA: University of Arizona, USA; WAT: University of Waterloo, Canada; GX: Geochron Laboratories, Krueger Enterprises.

región, y las variaciones de los perfiles de susceptibilidad magnética, en cuyos picos se identifican los horizontes de referencia $\mathrm{C} 2$ a C10 (Figura 6).

En el núcleo CHA-B se localizan los mayores espesores de las unidades y subunidades de las secuencias sedimentarias, por lo que para el conjunto de registros analizado representa la ubicación del depocentro, principalmente antes del depósito de la Unidad 2. Hacia el S del núcleo CHA-B en la cuenca lacustre, los espesores de la Unidad 3 se adelgazan (Figura 6). En la Unidad 3, los espesores de los depósitos lacustres no sólo son de mayor espesor en el núcleo CHA-B, también se encuentran a mayor profundidad. El espesor de los sedimentos entre los niveles de referencia C5 y C9 son casi $37 \%$ más delgados en el núcleo CHA11-VII que en el CHA-B. Por otra parte, el horizonte de referencia C10 se encuentra en el núcleo CHA-B a $4.7 \mathrm{~m}$ por debajo de su profundidad en el núcleo CHA11-VII, en tanto que la base de la $G C B$ presenta una diferencia de altura de $3.2 \mathrm{~m}$ entre ambos núcleos. El horizonte de la facies 8 entre 24.5 y 25.5 $\mathrm{m}$ de profundidad en el núcleo CHA11-VII, está ausente en el núcleo CHA-B. Es probable que una falla normal sinsedimentaria de dirección E-W entre la ubicación de los núcleos CHA-B y CHA-C, sea responsable del desfase de profundidad de los sedimentos (Figura 6). Este fallamiento sería paralelo a la falla Santa Catarina, inferida por VázquezSánchez y Jaimes-Palomera (1989). Considerando este desfase en la profundidad de los sedimentos, es probable que la edad de los $26.7 \mathrm{~m}$ de la secuencia en la columna compuesta colectada en los núcleos CHA08-II, CHA08-III y CHA11-VII alcancen una edad de $c a .60000$ cal A.P., que corresponde al inicio del estadio isotópico marino MIS 3 

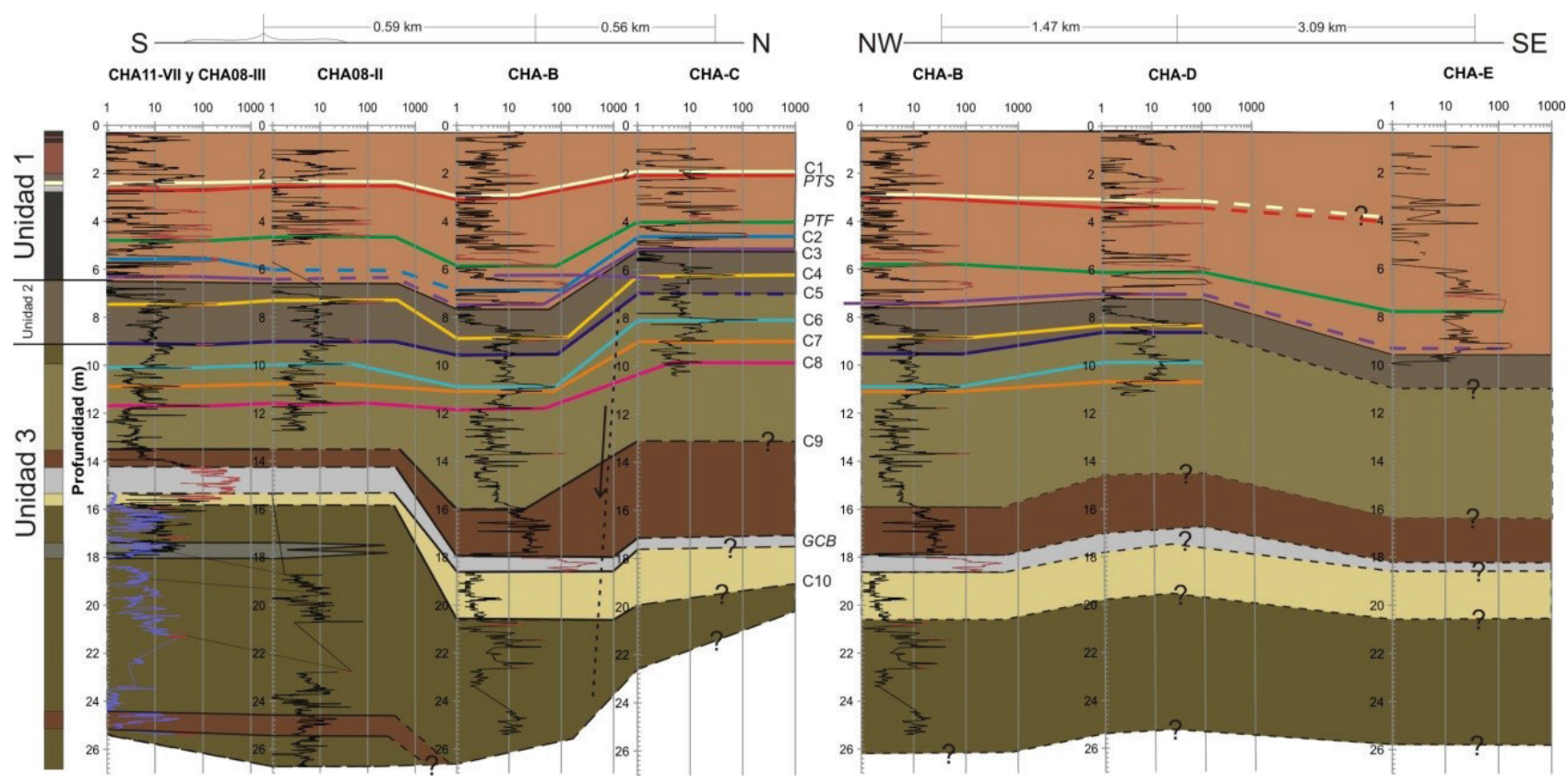

Figura 6. Correlación de facies de la secuencia estratigráfica lacustre de los $26.7 \mathrm{~m}$ superiores de Chalco en secciones S-N y NW-SE, a partir de los perfiles de la SM y horizontes marcadores (C1 a C10) y las tefras Pómez Toluca Superior (PTS, línea roja), Pómez Tutti Frutti (PTF, línea verde) y Gran Ceniza Basáltica ( $G C B$, área gris), de los núcleos discutidos en este trabajo. El perfil de la SM en azul corresponde a una porción del núcleo CHA08-III. Se indican las edades calibradas A.P. (cursivas) de los sondeos CHA-B y CHA-D. En la sección S-N, las facies de la Unidad 3 presentan los mayores espesores y se encuentran a mayor profundidad, por lo que se infiere una falla sinsedimentaria activa hasta antes del depósito de la Unidad 2. En la parte superior de cada sección se muestra la distancia entre cada pozo.

(Andersen et al., 2004).

En las unidades 2 y 1 disminuye la diferencia en los espesores y en la profundidad de los horizontes de referencia en las mismas, lo que sugiere el cese del fallamiento normal entre las unidades 2 y 3 . En los depósitos lacustres colectados en la parte N (núcleo CHA-C), el espesor de las unidades disminuye debido a menores tasas de sedimentación.

En dirección NW-SE sólo es posible analizar la continuidad lateral de los sedimentos por arriba del horizonte de referencia C3 (Figura 6). En esta dirección se observa el engrosamiento de aproximadamente $20 \%$ de las unidades superficiales 1 y 2 hacia el extremo SW, en el núcleo CHA-E. Entre la secuencia de los núcleos CHA-B y CHA-E, encontramos el adelgazamiento de todas las unidades en la secuencia del núcleo CHA-D. Así mismo, los horizontes de referencia $\mathrm{C} 2$ y $P T F$ están entre 2 y $2.4 \mathrm{~m}$ más profundos que en el núcleo CHA-E. Por otra parte, el horizonte de referencia $\mathrm{C} 1$ (ooze de diatomeas) está ausente en el núcleo CHA-E. Esto sugiere que ocasionalmente en épocas de bajos niveles de la lámina de agua, el lago de Chalco se separó en dos cuerpos al E y el W del Xico, de los cuales el del lado E ocupó una depresión ligeramente más profunda que la del sector $\mathrm{W}$.

El lago moderno indica la posición del actual depocentro, en el que se encuentra cercano al sitio del núcleo CHA-C. Del análisis de los registros, se desprende que el depocentro de la cuenca de Chalco se ha desplazado hacia el norte. De acuerdo con Ortiz-Zamora (2007), la depresión en la que se ubica el actual lago se debe a la subsidencia por la extracción de agua de catorce pozos, cuya operación inició en 1984.

\subsection{Registro de actividad volcánica y su impacto en el sistema lacustre.}

La historia de la actividad volcánica explosiva en la parte sur de la cuenca de México ha quedado registrada, al menos parcialmente, en las 18 capas individuales de ceniza reconocidas en los sedimentos lacustres de Chalco. Siebe y colaboradores $(2004,2005)$, han estimado que en los últimos 25000 años al menos 14 volcanes monogenéticos se han formado en la Sierra Chichinautzin, en tanto que en el mismo periodo han ocurrido al menos 7 erupciones plinianas del Popocatépetl y 2 del Nevado de Toluca. Esta actividad volcánica, ocurrida en la vecindad de la ciudad de México, tiene un periodo de recurrencia de $<1050$ años. En el núcleo CHA-B, entre la PTS (12319 cal A.P.) y el horizonte fechado en 30099 cal A.P. se reconocieron 11 tefras, lo que indica un periodo de recurrencia de actividad explosiva para este intervalo temporal de $c a$. 1600 años.

Esta estimación puede considerarse como un periodo de recurrencia mínimo, considerando que esta estimación abarca un periodo de $c a .17780$ años y no incluye los últimos $c a .12000$ años, así como también la posibilidad de que la actividad explosiva haya ocurrido fuera de la trayectoria de los vientos dominantes, o que el registro de la misma en la secuencia lacustre no haya sido conservada 
por procesos erosivos. Pese a ello, si se tiene en cuenta que la edad del volcán más joven de la Sierra Chichinautzin, el Xitle, tiene una edad de 1670 años A.P. (Siebe, 2000), la consideración del retraso en la siguiente erupción en la Sierra Chichinautzin propuesta por Siebe y colaboradores (2005), es reforzada por el registro de la secuencia lacustre en Chalco.

Para los depósitos volcánicos identificados en la secuencia lacustre analizada, la estructura volcánica que les dio origen es mayormente desconocida. Como se menciona anteriormente, las tefras utilizadas como marcadores estratigráficos en la región que han sido reconocidas en la secuencia lacustre analizada son las PTS del Nevado de Toluca, la PTF del Popocatépetl, y la llamada Gran Ceniza Basáltica, GCB o Tláhuac, cuyo origen se discute posteriormente. Otro marcador estratigráfico utilizado en la región es la Pómez Ocre, originada por el Popocatépetl (Arana-Salinas et al., 2010), a la cual podría corresponder el depósito de lapilli encontrado a los $10 \mathrm{~cm}$ del inicio de la secuencia sedimentaria. Sin embargo, ya que la planicie lacustre se ha usado de manera intensiva para la agricultura cuando no está cubierta por el cuerpo de agua, los sedimentos lacustres de la parte superior frecuentemente se encuentran perturbados y tanto la estratigrafía como las edades menores a 5 mil años son poco confiables, lo que dificulta el análisis de los depósitos más jóvenes.

El conjunto de depósitos volcaniclásticos asociados a la $G C B$ está caracterizado por presentar capas de hasta $18 \mathrm{~cm}$ de espesor de ceniza, intercaladas con bandas de sedimento compuesto por ceniza y limo (Tabla 1). En el núcleo CHA11-VII, los $65 \mathrm{~cm}$ inferiores contienen las capas de mayor espesor de ceniza, entre 5 y $18 \mathrm{~cm}$, y en los $31 \mathrm{~cm}$ superiores el espesor de las capas de ceniza disminuye, entre 10 y $5 \mathrm{~cm}$, y aumenta la frecuencia de las bandas de ceniza y limo. En todo este intervalo de $96 \mathrm{~cm}$, la susceptibilidad magnética presenta valores mayores a $100 \times 10^{-6}$ SI. En el núcleo CHA08-III, el espesor de este conjunto de depósitos volcaniclásticos es de $70 \mathrm{~cm}$, aunque es posible que en este núcleo el método de perforación haya compactado los sedimentos. En el núcleo CHA-B, el espesor de este depósito fue descrito originalmente de 54 cm (Lozano-García et al., 1993; Ortega-Guerrero y Newton, 1998); sin embargo, el intervalo que presenta valores de susceptibilidad mayores a $100 \times 10^{-6}$ SI es de $70 \mathrm{~cm}$. Esta secuencia no fue colectada en el núcleo CHA08-II, debido a problemas de recuperación durante la perforación. En otros sitios de las cuencas de Chalco y Texcoco se ha reconocido también este depósito volcaniclástico (Figura 7). En el sitio arqueológico de Tlapacoya, en el borde $\mathrm{N}$ de la cuenca de Chalco, tiene un espesor máximo de $55 \mathrm{~cm}$ (Lambert, 1986). En la cuenca de Texcoco, en el núcleo TxB tiene un espesor de $43 \mathrm{~cm}$ (Lozano García y Ortega Guerrero, 1998), en tanto que en Santa Isabel Iztapan el espesor observado fue de 17 cm (Huddart y González, 2006). Mooser (1997) reporta el reconocimiento de esta tefra en diferentes puntos de la ciudad de México, con espesores entre 60 y $40 \mathrm{~cm}$.

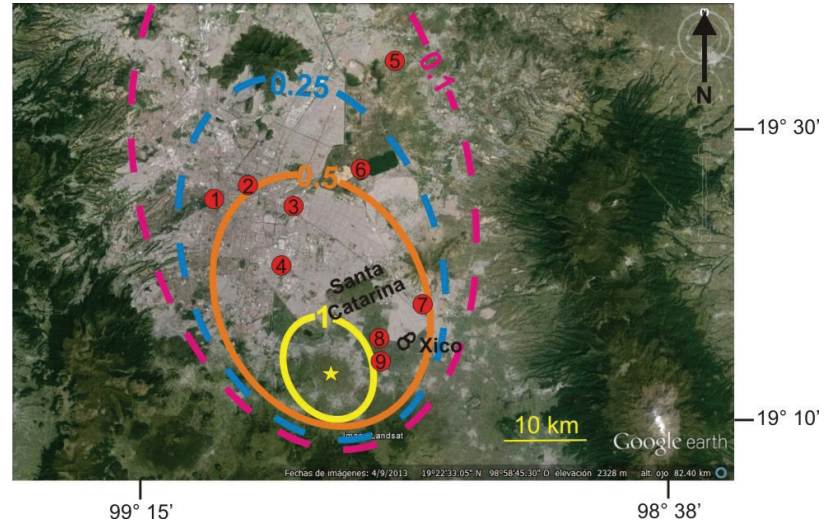

Figura 7. Mapa de isopacas sobre imagen de Google Earth de la tefra Gran Ceniza Basáltica $(G C B)$ o Tláhuac, de acuerdo a lo espesores reportados por diversos autores. 1) Esquina Reforma y Río Elba, 2) Catedral, 3) Pantitlán y 4) Cerro de la Estrella (Mooser, 1997); 5) Santa Isabel Iztapan (Huddart y González, 2006); 6) núcleo TxB (Lozano García y Ortega Guerrero, 1998); 7) Tlapacoya (Lambert, 1986); 8) núcleo CHA-B (Lozano-García et al., 1993); 9) núcleos CHA08-III y CHA11-VII (este trabajo). Se indica la localización de la Sierra de Santa Catarina y el anillo de toba Xico. La edad de la GCB está constreñida entre ca. 27000 y $41000 \mathrm{cal}$ AP.

El origen de la $G C B$ es aún desconocido. Mooser (1967) propuso que el origen de esta tefra podría ser el Popocatépetl y, posteriormente, la asocia a la Sierra de Santa Catarina (Mooser, 1997). Sin embargo, al analizar la distribución de los espesores reportados para esta tefra, se observa que el espesor de este depósito es mayor en las secuencias al S de la cuenca de Chalco (núcleos CHA08III y CHA11-VII), y disminuye hacia el N, lo que sugiere una fuente localizada hacia el $\mathrm{S}$ de los sondeos realizados. Consideramos que un probable origen de la misma es el volcán monogenéticoTeuhtli, cuyo cráter se encuentra a 6.5 km al SW de los núcleos CHA08-III y CHA11-VII (Figura 1b). El Teuhtli es una estructura volcánica que posee un cono de ceniza casi perfecto que se eleva por arriba de $460 \mathrm{~m}$ sobre la planicie lacustre, en la cima de un escudo de lava. Siebe y colaboradores (2005), reportan la presencia de las tefras PTF y la asociada Pómez Gris sobre un paleosuelo desarrollado a partir de los productos del Teuhtli, en tanto que un paleosuelo encontrado bajo los depósitos del volcán Teuhtli fue fechado en 34020 cal A.P. (Guilbaud et al., 2015). Esta edad es consistente con la estimación de la edad mencionada en la sección anterior para la $G C B$. De ser el Teuhtli el origen de la $G C B$, la distribución de las isopacas de esta tefra en las cuencas de Chalco y Texcoco podría ser como la ilustrada en el Figura 7.

El impacto que tuvo la acumulación de la $G C B$ en el sistema lacustre se observa tanto en la secuencia sedimentaria como en el registro de diatomeas. En el núcleo CHA11-VII, la falta de paralelismo en la estratificación y los lentes y cuñas de ceniza observados en los sedimentos que subyacen a esta tefra (Figura 2, facies 10), son debidos a la deformación por carga ejercida por el depósito de la tefra sobreyaciente y a la inyección del mismo material en los 
depósitos lacustres. En el registro de diatomeas del núcleo CHA-B (Caballero y Ortega Guerrero, 1998), antes de la caída de la $G C B$ las especies dominantes son de afinidad alcalina y halófilas, representadas por Nitzschia frustulum y Cyclotella meneghiniana, y las especies planctónicas están ausentes. Sin embargo, por arriba de la $G C B$, aparecen diatomeas planctónicas circumneutrales (especies pequeñas de Stephanodiscus, así como Stephanodiscus niagarae), lo que indica un ligero aumento en el nivel lacustre. Es probable que este aumento en el tirante del cuerpo de agua haya sido originado por una reducción en el volumen y la extensión de la cubeta lacustre por la acumulación de los materiales producidos por el Teuhtli.

Entre los ca. 22000 y 17000 cal A.P., el impacto de la actividad volcánica en el registro de diatomeas está marcado por alternancias de condiciones de agua dulce a ácidas (Caballero y Ortega Guerrero, 1998). Hacia el final del glacial ocurre el depósito de la $P T F$, cuyo efecto en el registro de diatomeas se observa únicamente como un ligero aumento en las especies planctónicas. Los cambios en las condiciones del lago posteriores al depósito de la $P T F$ parecen estar controlados por condiciones climáticas y no a consecuencia del emplazamiento de esta tefra.

El efecto que pudo tener en el lago la actividad de las estructuras volcánicas más cercanas a la planicie lacustre es incierto, ya que no existen fechamientos absolutos de sus depósitos. Entre estas estructuras de edad sin determinar se encuentran los domos que forman la Sierra de Santa Catarina, que constituyen la divisoria $\mathrm{N}$ de la cuenca de Chalco, ubicados a una distancia mínima de $8.5 \mathrm{~km}$ de los núcleos CHA08-II, CHA08-III y CHA11-VII. Martin del Pozzo (1990), y Lugo-Hubp y colaboradores (1994), consideran que la actividad más joven de esta sierra puede ser cercana a 20000 años. Otra de estas estructuras volcánicas es el anillo de toba del Xico, emplazado en la parte central de la planicie lacustre, a $3.75 \mathrm{~km}$ de los núcleos CHA08-II, CHA08-III y CHA11-VII. Sobre ella ha sido reconocida la tefra $P T F$ (C. Siebe, com. personal, febrero 2014), lo que indica que tiene una edad anterior a $17670 \mathrm{cal}$ A.P. En el registro analizado no se reconoce una perturbación mayor que pueda estar asociado a la formación de algunos de estos aparatos volcánicos.

\section{Conclusiones}

Se identificaron trece facies en los núcleos recuperados en las campañas de 2008 - 2011, que se han agrupado en tres clases principales, de acuerdo a sus componentes más abundantes: facies clásticas, facies volcaniclásticas y facies biogénicas.

La extrapolación lineal de las edades de la secuencia sedimentaria colectada en el núcleo CHA-B indica que los $26 \mathrm{~m}$ superiores de sedimentos tienen una edad aproximada de 51000 cal A.P., y la secuencia compuesta colectada en los núcleos CHA08-II, CHA08-III y CHA11-VII podría alcanzar 60000 cal A.P., que corresponde al inicio del MIS 3.

En el núcleo CHA-B se localizan los mayores espesores de las unidades y subunidades de las secuencias sedimentarias, por lo que para el conjunto de registros analizado representa la ubicación de depocentro, principalmente antes del depósito de la Unidad 2. La arquitectura de los sedimentos lacustres de Chalco ha estado controlada por cambios en la cubeta lacustre causados por el emplazamiento de productos volcánicos, subsidencia tectónica, y subsidencia por la extracción de agua a través de pozos en época histórica.

Es probable que un fallamiento normal sinsedimentario de dirección E-W entre la ubicación de los núcleos CHA-B y CHA-C, sea el responsable de la arquitectura de los sedimentos. Este fallamiento normal estuvo activo en la Unidad 3, pero cesa su actividad entre las unidades 2 y 3 , es decir alrededor de los ca. $26500 \mathrm{cal}$ A.P.

La actividad volcánica registrada entre 12319 y 30099 cal A.P. en los sedimentos lacustres de Chalco tiene un periodo de recurrencia $c a .1600$ años, que resulta cercana a la edad del Xitle, el más joven en la Sierra Chichinautzin, lo que refuerza la idea del retraso en la siguiente erupción en este campo monogenético (Siebe et al., 2005).

La edad estimada y la distribución de la Gran Ceniza Basáltica en las cuencas de Chalco y Texcoco indican que su origen más probable sea el volcán Teuhtli. El depósito de esta tefra en el sitio del núcleo CHA11-VII deformó y perturbó la sedimentación lacustre previa. El aumento de diatomeas planctónicas en el núcleo CHA-B sugiere una disminución en la extensión de la cubeta lacustre, acompañada de ligero aumento en el tirante de agua.

La documentación de la actividad volcánica durante el Cuaternario en el sur de la cuenca de México representa un reto para el conocimiento de la evolución geológica de la región. Los esfuerzos que se llevan a cabo en los últimos años por diversos autores para establecer una detallada tefracronología de esta región, a los que se suman los análisis en curso de los depósitos volcánicos intercalados en la secuencia sedimentaria lacustre, facilitarán la identificación del origen y la determinación de la edad de la actividad volcánica en la vecindad de la cuenca de México.

\section{Agradecimientos}

Este trabajo fue posible gracias al financiamiento de los proyectos de la Universidad Nacional Autónoma de México (UNAM) DGAPA-PAPIIT IN220609, IN109012, IN101513 y IN107013, así como del CONACyT 130963. Agradecemos a Anders Noren y Kristina Brady, del LacCore, University of Minnessota, por su asistencia en la documentación inicial de los núcleos. También agradecemos a Alejandro Rodríguez, Antonio González, Susana Sosa y Daniel Villanueva por su ayuda en la obtención de núcleos. Teodoro Hernández asistió en la fabricación de herramientas y en el apoyo logístico para llevar a cabo la perforación de núcleos. D. Herrera Hernández, gozó de una beca del 
Instituto Panamericano de Geografía e Historia y obtuvo apoyo del Posgrado en Ciencias de la Tierra (UNAM), para llevar a cabo sus estudios de maestría. Los autores agradecen a Juana Vegas y Blas Valero por sus comentarios y sugerencias, que contribuyeron a mejorar este trabajo.

\section{Referencias}

Andersen, K., Azuma, N., Barnola, J.M., Bigler, M., Biscaye, P., Caillon, N., Chappellaz, J., Clausen, H.B., Dahl-Jensen, D., Fischer, H., Flückiger, J., Fritsche, D., Fujii, Y., Goto-Azuma, K., Gronvold, K., Gundestrup, N.S., Hansson, M., Huber, C., Hvidberg, C.S., Johnsen, S.J., Jonsell, U., Jouzel, J., Kipfstuh, S., Landais, A., Leuenberger, M., Lorrain, R., Masson-Delmotte, V., Miller, H., Motoyama, H., Narita, H., Popp, T., Rasmussen, S.O., Raynaud, D., Rothlisberger, R., Ruth, U., Samyn, D., Schwander, J., Shoji, H., Siggard-Andersen, M-L., Steffensen, J.P., Stocker, T., Sveinbjörnsdóttir, A.E., Svensson, A., Takata, M., Tison, J.L., Thorsteinsson, Th., Watanabe, O., Wilhelms, F., White, J.W.C., 2004, High-resolution record of Northern Hemisphere climate extending into the last interglacial period: Nature, 431, 147-151.

Arana-Salinas, L., Siebe, C., Macías, J.L., 2010, Dynamics of the ca. $4965 \mathrm{yr}{ }^{14} \mathrm{C}$ BP "Ochre Pumice" Plinian eruption of Popocatépetl volcano, México: Journal of Volcanology and Geothermal Research, 192, 212-231.

Arce, J.L., Macías, J.L., Vázquez-Selem, L., 2003, The 10.5 ka Plinian eruption of Nevado de Toluca volcano, Mexico: Stratigraphy and hazard implications: Geological Society of America Bulletin, 115 (2), 230-248

Arce, J.L., Cervantes, K.E., Macías, J.L., Mora, J.C., 2005, The 12.1 ka Middle Toluca Pumice: A dacitic Plinian-subplinian eruption of Nevado de Toluca in Central Mexico: Journal of Volcanology and Geothermal Research, 147 (1-2), 125-143.

Arce, J.L., Macias, J.L., Gardner, J.E., Layer, P.W., 2006, A 2.5 ka History of Dacitic Magmatism at Nevado de Toluca, Mexico: Petrological, ${ }^{40} \mathrm{Ar} /{ }^{39} \mathrm{Ar}$ Dating, and Experimental Constraints on Petrogenesis: Journal of Petrology, 47 (3), 457-479.

Arce, J.L., Layer, P.W., Lassiter, J.C., Benowitz, J., Macías, J.L., RamírezEspinosa, J., 2013, ${ }^{40} \mathrm{Ar} /{ }^{39} \mathrm{Ar}$ dating, geochemistry, and isotopic analyses of the quaternary Chichinautzin volcanic field, south of Mexico City: implications for timing, eruption rate, and distribution of volcanism: Bulletin of Volcanology, 75, 1-25.

Bloomfield, K., 1975, A late Quaternary monogenetic volcanic field in central Mexico: Geologischen Rundschau, 64 (1), 476-497.

Bloomfield, K., Valastro, S., 1977, Late Quaternary tephrochronology of Nevado de Toluca volcano, Central Mexico: Overseas Geology and Mineral Resources, 46, $15 \mathrm{p}$.

Bradbury, J.P., 1989, Late Quaternary lacustrine paleoenvironments in the Cuenca de México: Quaternary Science Reviews, 8 (1), 75-100.

Caballero-Miranda, M.E., 1995, Late Quaternary palaeolimnology of lake Chalco, the basin of Mexico: Hull, United Kingdom, University of Hull, tesis doctoral, $286 \mathrm{p}$.

Caballero, M., Ortega Guerrero, B., 1998, Lake levels since about 40000 years ago at Lake Chalco, near Mexico City: Quaternary Research, $50(1), 69-79$.

Campos Enríquez, O., Delgado Rodríguez, O., Chávez Segura, R., Gómez Contreras, P., Flores Márquez, L., Birch, F.S., 1997, The surface of Chalco sub-basin (Mexico City) inferred from geophysical data: Geophysics, 62 (1), 23-35.

Correa-Metrio, A., Bush, M., Lozano-García, S., Sosa-Nájera, S., 2013, Millenial-scale temperature change velocity in the continental northern neotropics: PLoS ONE, 8 (12), e81958. Doi:10.1371/ journal.pone.0081958.

Cserna, Z., Fuente-Duch, M., Palacios-Nieto, M., Truay, L., Mitre-Salazar, M., Mota-Palomino, R., 1988, Estructura geológica, gravimetría, sismicidad y relaciones neotectónicas regionales de la cuenca de México: Boletín del Instituto de Geología, 104, 71.

Espinasa-Pereña, R., Martin-del Pozo, A., 2006, Morphostratigraphic evolution of Popocatépetl volcano, México: Geological Society of America, 402, 101-123.

Fries, C., 1962, Bosquejo geológico de las partes central y occidental del estado de Morelos y áreas contiguas de guerreo y México (resumen), México D.F., en $20^{\text {th }}$ International Geological Congress: México, Universidad Nacional Autónoma de México, 17-53.

García-Palomo, A, Macias, J.L., Arce, J.L., Capra, L., Garduño, V.H., Espíndola, J.M., 2002, Geology of Nevado de Toluca volcano and surrounding areas, central Mexico: Geological Society of America Map and Chart Series MCH089, 1-26.

Guilbaud, M.N., Arana-Salinas, L., Siebe, C., Barba-Pingarrón, L.A., Ortiz, A., 2015, Volcanic stratigraphy of a high-altitude Mammuthus columbi (Tlacotenco, Sierra Chichinautzin), Central México, Bulletin of Volcanology, 77 (3), 17, DOI 10.1007/s00445-0150903-5.

Herrera-Hernández, D., 2011, Estratigrafía y análisis de facies de los sedimentos lacustres del Cuaternario tardío en la cuenca de Chalco, México: México, D.F., Universidad Nacional Autónoma de México, tesis de maestría, $122 \mathrm{p}$.

Huddart, D., González, S., 2006, A review of environmental change in the Basin of Mexico (40000-10000 B.P.) implications for early humans, en Jiménez López, J.C., Pompa y Padilla, J.A., Gonzalez, S., Ortiz, F. (eds), Proceedings of the $1^{\text {st }}$ International Symposium Early Humans in America: Instituto Nacional de Antropología e Historia Colección Científica Serie Antropología, 500, 77-105.

Iglesias, M., 1902, Memoria histórica, técnica y administrativa de las obras del desagüe del Valle de México 1449-1900: México Oficina impresora de estampillas, $480 \mathrm{p}$.

Lambert, W., 1986, Descripción preliminar de los estratos de tefra de Tlapacoya I, en Lorenzo J.L, Mirambell, L. (eds), Tlapacoya: 35000 años de historia del Lago de Chalco: Instituto Nacional de Antropología e Historia Colección Científica, 155, 77-100.

Lorenzo, J.L., Mirambell, L., 1989, Tlapacoya: 35000 años de historia del Lago de Chalco: México, Instituto Nacional de Antropología e Historia Colección Científica, 155, 297 p.

Lozano-García, M.S., Ortega-Guerrero, B., Caballero-Miranda, M., Urrutia-Fucugauchi, J., 1993, Late Pleistocene and Holocene paleoenvironments of Chalco lake, central Mexico: Quaternary Research, 40, 332-342.

Lozano-García, M.S., Ortega-Guerrero, B., 1998, Late Quaternary environmental changes of the central part of the Basin of Mexico; correlation between Texcoco and Chalco basins: Review of Paleobotany and Palynology, 99, 77-93.

Lugo Hupb, J., 1984, Geomorfología del Sur de la Cuenca de México: Instituto de Geografía, UNAM, México, Serie Varia, 1 (8), 95 p.

Lugo-Hubp, J., Mooser, F., Pérez-Vega, A., Zamorano-Orozco, J., 1994, Geomorfología de la Sierra de Santa Catarina, D.F., México: Revista Mexicana de Ciencias Geológicas, 11, 43-52.

Martin del Pozzo, A.L., 1982, Monogenetic volcanism in Sierra Chichinautzin, Mexico: Bulletin of Volcanology, 45 (1), 9-24.

Martin del Pozzo, A.L., 1990, Geoquímica y paleomagnetismo de la Sierra de Chichinautzin: México: México, D.F., Universidad Nacional Autónoma de México, tesis doctoral, $235 \mathrm{p}$.

Mooser, F., 1967, Tefracronología de la Cuenca de México para los últimos treinta mil años: Boletín Instituto Nacional de Antropología e Historia, 30, 12-15.

Mosser, F., 1997, Nueva fecha para la tefracronología de la Cuenca de México, en Carballal-Staedtler M. (ed), A propósito del cuaternario: Dirección de Salvamento Arqueológico: México, D.F., Instituto Nacional de Antropología e Historia, 137-141.

Mooser, F., González-Rul, F., 1961, Erupciones volcánicas y el hombre primitivo en la Cuenca de México (resumen), en Homenaje a Pablo Martínez del Río en el XXV aniversario de la edición de los Orígenes Americanos: México, D.F., Instituto Nacional de Antropología e Historia de México, 137-141. 
Ortega Guerrero, B., 1992, Paleomagnetismo, magnetoestratigrafía y paleoecología del Cuaternario tardío en el lago de Chalco, cuenca de México: México, D.F., Universidad Nacional Autónoma de México, tesis doctoral, $161 \mathrm{p}$.

Ortega-Guerrero, B., Newton, A.J., 1998, Geochemical Characterization of Late Pleistocene and Holocene Tephra Layers from the Basin of Mexico, Central Mexico: Quaternary Research. 50, 90-106.

Ortega-Guerrero, B., Thompson, R., Urrutia-Fucugauchi, J., 2000, Magnetic properties of lake sediments from Lake Chalco, central Mexico, and their palaeoenvironmental implications: Journal of Quaternary Science, 15 (12), 127-140.

Ortiz-Zamora, D., 2007, Fracturamiento en el acuitardo lacustre que cubre al acuífero regional de la ciudad de México: origen, dinámica e implicaciones: México, D.F., Universidad Nacional Autónoma de México, tesis doctoral, $158 \mathrm{p}$.

Pi, T., Lozano-García, S., Caballero-Miranda, M., Ortega-Guerrero, B., Roy, P., 2010, Discovery and characterization of a struvite layer in the Chalco paleolake, Mexico: Revista Mexicana de Ciencias Geológicas, 27 (3), 573-580.

Reimer, P.J., Bard, E., Bayliss, A., Beck, J.,W., Blackwell, P.G., Ramsey, C.B., Buck, C.E.,Cheng, H.,Edwards, R.L.,Friedrich, M., Grootes, P.M., Guilderson, T.P., Haflidason, H., Hajdas, I., Hatté, C., Heaton, T.J., Hoffmann, D.L., Hogg, A.G., Hughen, K.A., Kaiser, K.F., Kromer, B., Manning, S.W., Niu, M., Reimer, R.W., Richards, D.A., Scott, E.M., Southon, J.R., Staff, R.A., Turney, C.S.M., van der Plicht, J., 2013, INTCAL13 and MARINE13 Radiocarbon age calibration curves 0-50000 years cal BP: Radiocarbon, 55 (4), 1869-1887.

Rodríguez-Chávez, F.M., 2003, Modelado gravimétrico de la estructura de la cuenca de México: México, D.F., Universidad Nacional Autónoma de México, tesis de licenciatura, $98 \mathrm{p}$.

Rueda, H., Macías, J.L., Arce, J.L, Gardner, J.E., Layer, P.W., 2013, The $\sim 31$ ka rhyolitic Plinian to sub-Plinian eruption of Tlaloc Volcano, Sierra Nevada, central Mexico: Journal of Volcanology and Geothermal Research, 252, 73-91.

Sáez, A., Valero-Garcés, B.I., Moreno, A., Bao, R., Pueyo, J., GonzálezSampériz, P., Giralt, S., Taberner, C., Herrera, C.,Gibert, R.O., 2007, Lacustrine sedimentation in active volcanic setting: the late Quaternary depositional evolution of Lake Chungará (northern Chile): Sedimentology, 54, 1191-1222.

Schnurrenberger, D., Russell, J., Kelts, K., 2003, Classification of lacustrine sediments based on sedimentary components: Journal of Paleolimnology, 29, 141-154.
Siebe, C., 2000, Age and archaeological implications of Xitle volcano, southwestern basin of Mexico City: Journal of Volcanology and Geothermal Research, 104 (1-4), 45-64.

Siebe, C., Abrams, M., Macías, J.L., Obenholzner, J., 1996, Repeated volcanic disasters in Prehispanic time at Popocatépetl, central Mexico: past key to the future?: Geology, 24 (5), 399-402.

Siebe, C., Macias, J.L, 2004, Volcanic hazards in the Mexico City metropolitan area from eruptions at Popocatépetl, Nevado de Toluca, and Jocotitlán stratovolcanoes and monogenetic scoria cones in the Sierra Chichinautzin Volcanic Filed: Geological Society of America Special Papers, 402, 253-329.

Siebe, C., Rodriguez-Lara, V., Schaaf, P., Abrams, M., 2004, Radiocarbon ages of Holocene Pelado, Guespalapa, and Chichinautzin scoria cones, south of Mexico City: implications for archaeology and future hazards: Bulletin of Volcanology, 66, 203-225.

Siebe, C., Arana-Salinas, L., Abrams, M., 2005, Geology and radiocarbon ages of Tláloc, Tlacotenco, Cuauhtzin, Hijo del Cuauhtzin, Teuhtli, and Ocusacayo monogenetic volcanoes in the central part of the Sierra Chichinautzin, México: Journal of Volcanology and Geothermal Research, 141, 225-243.

Sosa-Nájera, S., 2001, Registro palinológico del Pleistoceno tardíoHoloceno en el extremo meridional de la cuenca de México: paleoambientes e inferencias paleoambientales: México, D.F, Universidad Nacional Autónoma de México, tesis de maestría, $115 \mathrm{p}$.

Urrutia-Fucugauchi, J., Chávez-Segura, R.E., 1991, Gravity modeling of lake basin structure: the lakes of Xochimilco and Chalco, southern basin of Mexico (resumen), en USA Society of Exploration Geophysicist Annual Meeting Proceedings, Expanded Abstracts Book, 61, 611-613.

Valero-Garcés, B.L., Grosjean, M., Kelts, K., Schreier, H., Messerli, B., 1999, Holocene lacustrine deposition in the Atacama Altiplano: facies model, climate and tectonic forcing: Palaeogeography, Palaeoclimatology, Palaeoecology, 151 (3), 101-125.

Vázquez-Sánchez, E., Jaimes-Palomera, R., 1989, Geología de la Cuenca de México: Geofísica Internacional, 28 (2), 133-190.

Manuscrito recibido: Abril 29, 2014.

Manuscrito corregido recibido: Diciembre 5, 2014.

Manuscrito aceptado: Febrero 2, 2015. 